\title{
Squamanitaceae and three new species of Squamanita parasitic on Amanita basidiomes
}

\author{
Jian-Wei Liu ${ }^{1,2}$, Zai-Wei Ge ${ }^{1,3}$, Egon Horak ${ }^{4}$, Alfredo Vizzini ${ }^{5}$, Roy E. Halling ${ }^{6}$, Chun-Lei Pan ${ }^{7}$ and Zhu L. Yang ${ }^{1,3^{*}}$ (D)
}

\begin{abstract}
The systematic position of the enigmatically mycoparasitic genus Squamanita (Agaricales, Basidiomycota) together with Cystoderma, Phaeolepiota, Floccularia, and Leucopholiota is largely unknown. Recently they were recognized as Squamanitaceae, but previous studies used few DNA markers from a restricted sample of taxa from the family and lacked a formal taxonomic treatment. In this study, with newly generated sequences of the type of the genus Squamanita, S. schreieri, and several additional species of the family, the phylogeny is reinvestigated with a concatenated (18S-5.8S-nrLSU-RPB2-TEF1-a) dataset. This study reveals that Cystoderma, Phaeolepiota, Squamanita, Floccularia, and Leucopholiota are a monophyletic clade with strong statistical support in Bayesian analysis and form Squamanitaceae. Phaeolepiota nested within Cystoderma; Squamanita, Leucopholiota, and Floccularia clustered together as two monophyletic subclades; and Squamanita was present as a monophyletic clade with strong statistical support in both Maximum Likelihood and Bayesian analyses. The family name Squamanitaceae is formally emended and a detailed taxonomic treatment is presented to accommodate the five genera. Meanwhile, another concatenated (18S-ITS-nrLSU-RPB2-TEF1-a) dataset is used to investigate phylogenetic relationships and species delimitation in Squamanita. Our data indicates that "S. umbonata" from the Northern hemisphere forms two species complexes, one complex includes six specimens from North America, Europe, and East Asia, the other includes two specimens from Central America and North America respectively. Futhermore, species of Squamanita can parasitize species of Amanita, besides other fungal species. Squamanita mira parasitizes A. kitamagotake (A. sect. Caesareae), while S. orientalis and S. sororcula are parasites of species belonging to the A. sepiacea complex (A. sect. Validae). "Squamanita umbonata" from Italy occurs on A. excelsa (A. sect. Validae). Three new species of Squamanita from East Asia, viz. S. mira, S. orientalis and S. sororcula are documented with morphological, multi-gene phylogenetic, and ecological data, along with line drawings and photographs, and compared with similar species. A key for identification of the global Squamanita species is provided.
\end{abstract}

Keywords: Amanita, Mycoparasitic fungi, Squamanita, Host preference, Three new taxa

\footnotetext{
* Correspondence: fungi@mail.kib.ac.cn

${ }^{1}$ Yunnan Key Laboratory for Fungal Diversity and Green Development, Kunming Institute of Botany, Chinese Academy of Sciences, Kunming 650201, Yunnan, China

${ }^{3}$ CAS Key Laboratory for Plant Diversity and Biogeography of East Asia, Kunming Institute of Botany, Chinese Academy of Sciences, Kunming 650201, Yunnan, China

Full list of author information is available at the end of the article
}

(c) The Author(s). 2021 Open Access This article is licensed under a Creative Commons Attribution 4.0 International License, which permits use, sharing, adaptation, distribution and reproduction in any medium or format, as long as you give appropriate credit to the original author(s) and the source, provide a link to the Creative Commons licence, and indicate if changes were made. The images or other third party material in this article are included in the article's Creative Commons licence, unless indicated otherwise in a credit line to the material. If material is not included in the article's Creative Commons licence and your intended use is not permitted by statutory regulation or exceeds the permitted use, you will need to obtain permission directly from the copyright holder. To view a copy of this licence, visit http://creativecommons.org/licenses/by/4.0/. 


\section{INTRODUCTION}

Squamanita is one of the most enigmatic genera of the Agaricales (Halama 2016; Mondiet et al. 2007; Redhead et al. 1994), and the members of this genus are extremely rare and sporadic all over the world (Griffith et al. 2019; Holden 2005; Matheny and Griffith 2010). Squamanita was originally described from riverine forest in Switzerland. After examining the type material, Horak (1968) presented a full re-description of the microscopic characters including features not reported in the protologue. Almost all the species of Squamanita are biotrophic parasites on other agaric species (Halama 2016; Harmaja 1987; Henrici 2013; Matheny and Griffith 2010; Nagasawa et al. 1990; Redhead et al. 1994; Reid 1983). The basidiomes of Squamanita grow from other agaric species and deform the host basidiomes so that they become incorporated into an enlarged base of the stipe of the Squamanita. Eventually, the host is completely deformed and more or less unrecognizable (Halama 2016; Redhead et al. 1994). Parasitized host tissue has been labelled as "sclerotial bodies", "protocarpic tubers" (Bas 1965; Singer 1986), "galls" (Redhead et al. 1994), "cecidiocarp" (Bas and Thoen 1998) or "mycocecidium" (Griffith et al. 2019; Vizzini and Girlanda 1997), and sometimes multiple basidiomes come out from a "mycocecidium" (Bas 1965; Mondiet et al. 2007).

To date, 12 species of Squamanita have been accepted in the current literature (http://www.indexfungorum.org/ Names/names.asp; Fraiture et al. 2019). It is reported that these species can parasite at least seven different genera of Agaricales, viz. Amanita (Bas 1965; Redhead et al. 1994), Cystoderma (Griffith et al. 2019; Harmaja 1987; Holden 2005; Matheny and Griffith 2010; Redhead et al. 1994; Reid 1983; Singer 1986), Galerina (Redhead et al. 1994), Hebeloma (Bas and Læssøe 1999; Mondiet et al. 2007; Vesterholt 1991), Inocybe (Vizzini and Girlanda 1997), Kuehneromyces (Cervini 2008; Gulden et al. 1977), Phaeolepiota (Nagasawa et al. 1990; Redhead et al. 1994), and possibly also Mycena (Stridvall 1994).

The genus Squamanita was assigned on the basis of morphology to different families in the past, including Squamanitaceae and Cystodermataceae. Based on phylogenetic analysis of combined nuclear ribosomal RNA genes, Matheny and Griffith (2010) suggested that Squamanita, Cystoderma, and Phaeolepiota represent a monophyletic clade. In the subsequent molecular works by Matheny et al. (2015), Griffith et al. (2019) and Vizzini et al. (2019), Squamanita and allied genera were referred as Squamanitaceae. Recently, Squamanita, Cystoderma, Phaeolepiota, Floccularia, and Leucopholiota were classified into Squamanitaceae (http://www.agaric.us) (Kalichman et al. 2020), but without a formal taxonomical treatment. In addition, the host species of Squamanita have been identified mainly based on morphological data and ecological evidence (Bas
1965; Mondiet et al. 2007), except for a few studies (Griffith et al. 2019; Matheny and Griffith 2010; Mondiet et al. 2007), which used molecular phylogenetic techniques to identify the hosts.

In the survey of macrofungi in China, we collected three species of Squamanita and two collections of Amanita sect. Caesareae and one collection of A. sect. Validae (Cui et al. 2018) with similar "mycocecidia" of two Squamanita species in the nearby localities respectively. To validate the taxonomical, phylogenetic and ecological traits, detailed morphological and anatomical studies and molecular phylogenetic analyses are carried out. To understand the species recorded in China, additional specimens collected in other parts of the world are examined and included in the present report.

\section{MATERIAL AND METHODS}

Morphology, sampling, DNA extraction, PCR amplification and sequencing

Specimens studied are listed in Tables 1 and 2. For morphological study, we follow Cui et al. (2018) and the references therein. To verify the mycoparasitic features of the target species, routine samples (HKAS100826) for DNA extraction were separately taken both from the basidiome (five samples for basidiome labeled from $\mathrm{C} 1$ to $\mathrm{C} 5$ ) and the mycocecidium (six samples labeled from B1 to B6 as illustrated in Fig. 6). In addition, samples of other specimens were taken from different locations from their basidiomes and mycocecidia respectively, and then mixed for improving the success probability of DNA extraction in case of poor sample quality. Particularly, the volval remnant-like structure on the cap of the Squamanita specimen (HKAS74862A) was sampled. All Chinese collections are deposited in the Herbarium of Cryptogams of Kunming Institute of Botany, Chinese Academy of Sciences, China (HKAS).

The total genomic DNA of all the materials of the parasitic species and the coexisting Amanita species was extracted by using the Extract-N-Amp kit (Sigma, USA). Universal primer pairs LROR/LR5 (Vilgalys and Hester 1990), ITS1F/ITS4 (Gardes and Bruns 1993; White et al. 1990), PNS1/NS41 (Bruns lab; Hibbett 1996) and NS51/ NS8 (Bruns lab; White et al. 1990), and EF1-983F/EF11567R (Rehner and Buckley 2005), RPB2-6F/RPB2-7R (Hall lab), RPB1-Af/RPB1-Dr (Hall lab) were used for amplifying the large nuclear ribosomal RNA subunit (nrLSU), the internal transcribed spacers 1 and 2 with the 5.8S rDNA (ITS), the small subunit (18S) region, translation elongation factor $1-\alpha$ (TEF1- $\alpha)$, the RNA polymerase II second largest subunit (RPB2), and RNA polymerase II largest subunit (RPB1) respectively.

PCR products which failed in direct sequencing were firstly purified with the Cycle-pure-kit (Omega, USA) or Gel Extraction and PCR Purification Combo Kit 


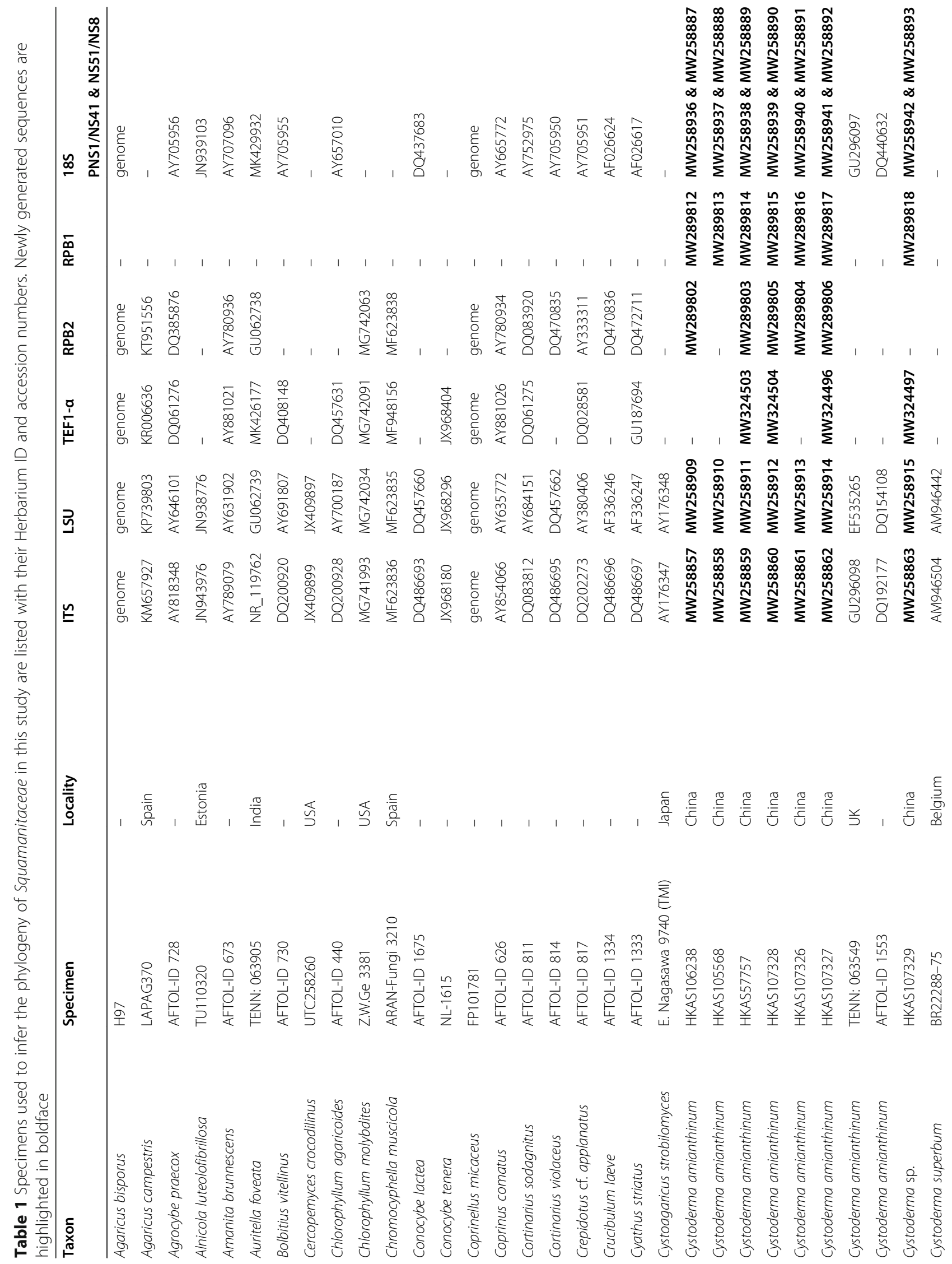




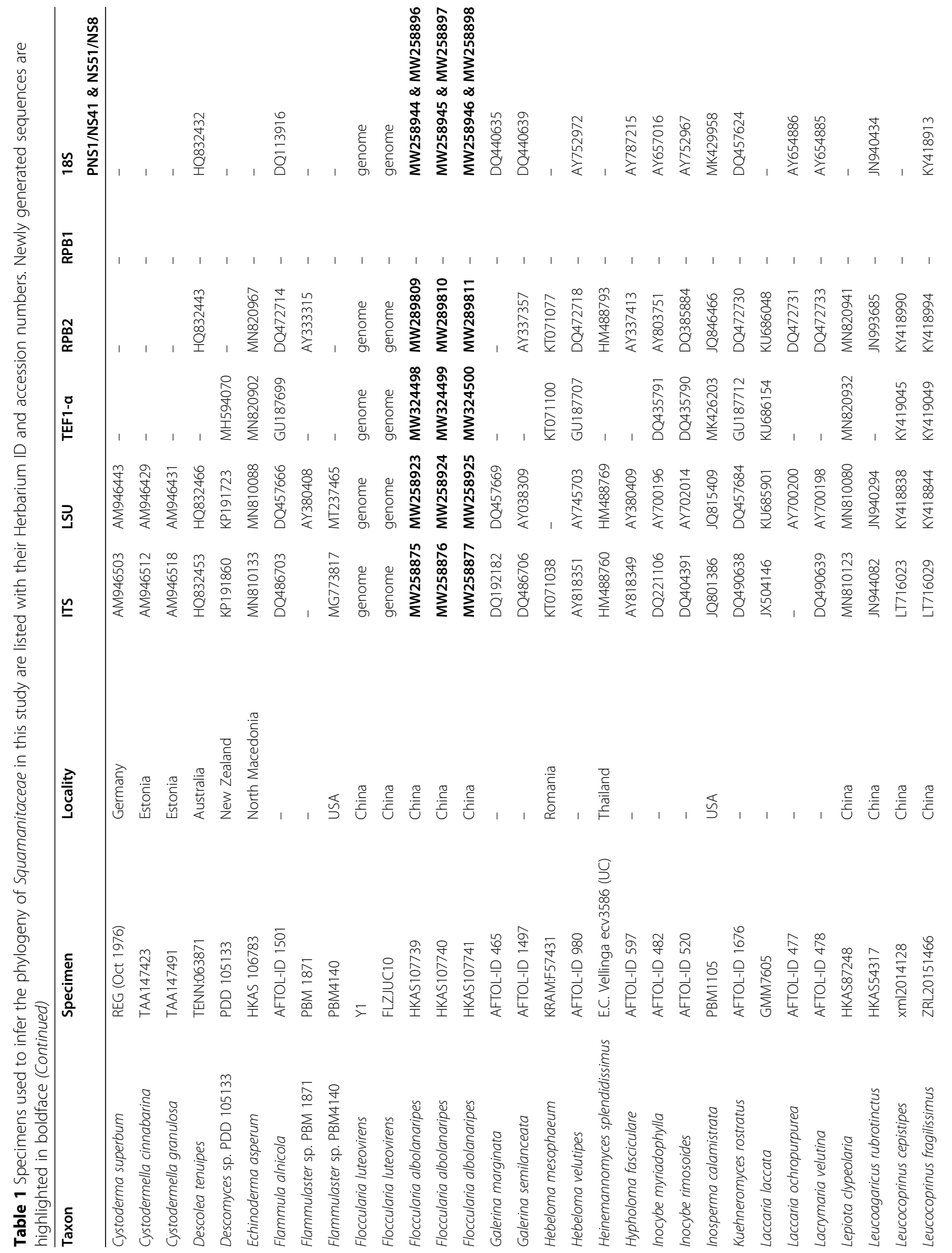




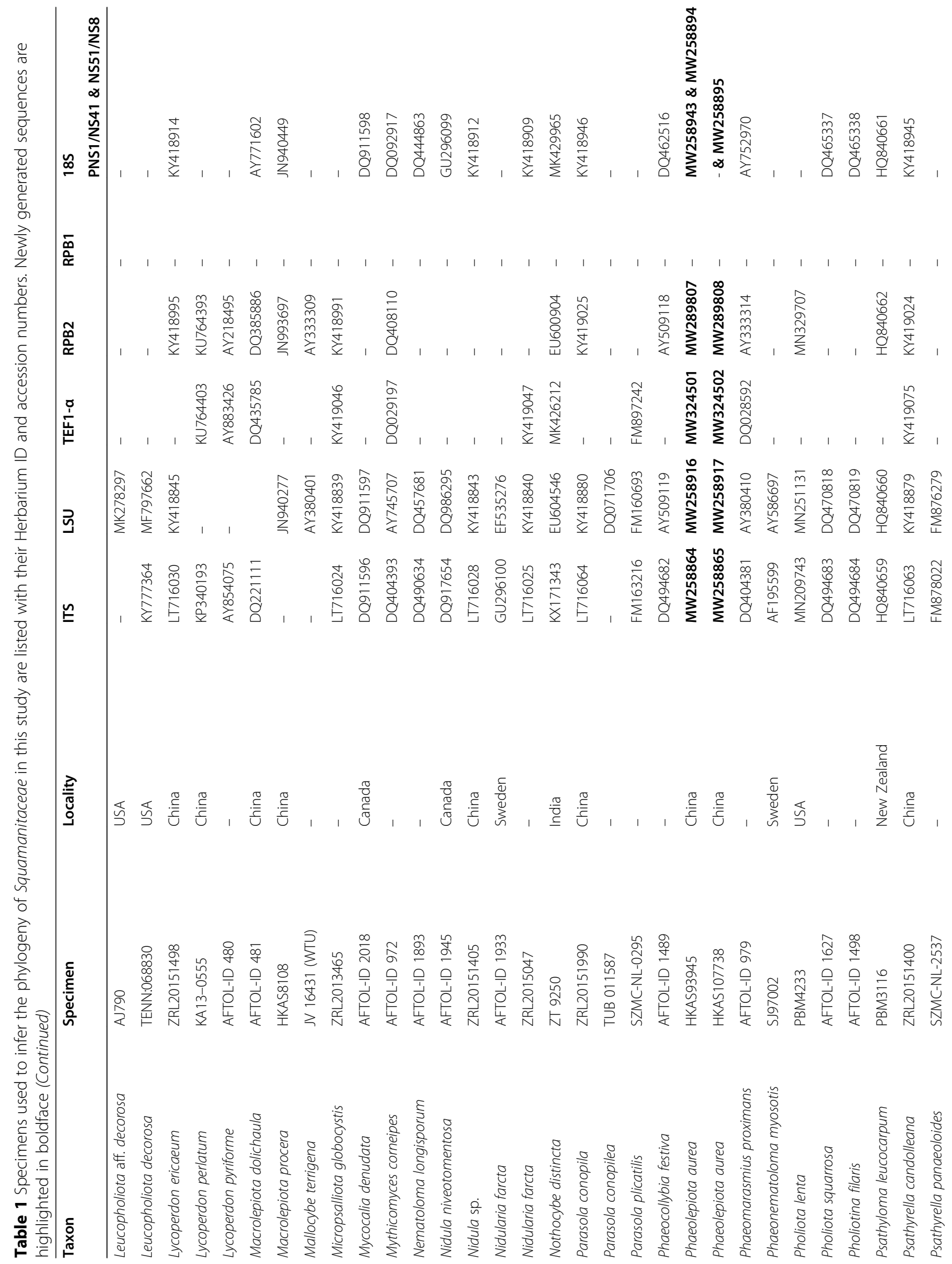




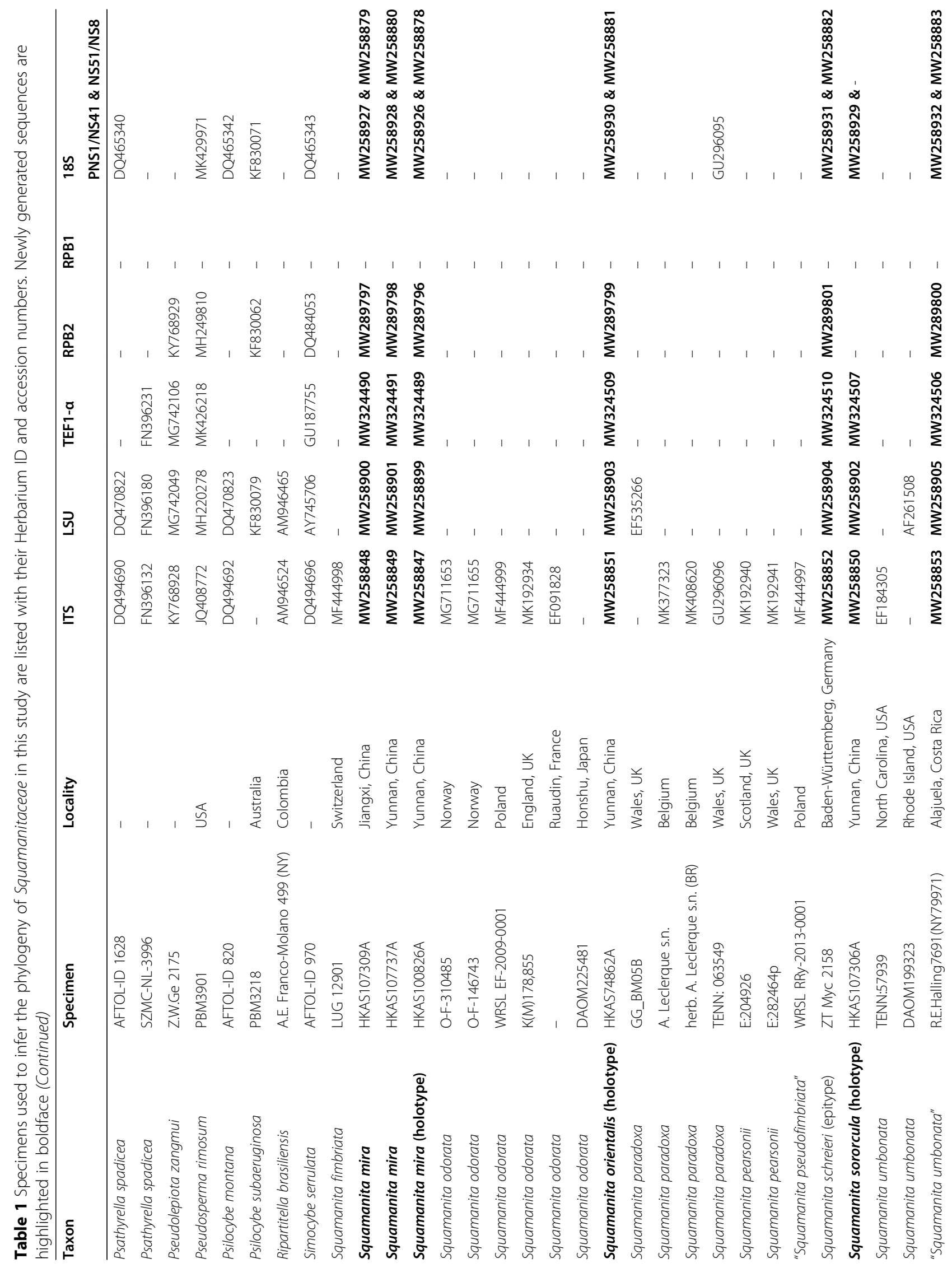




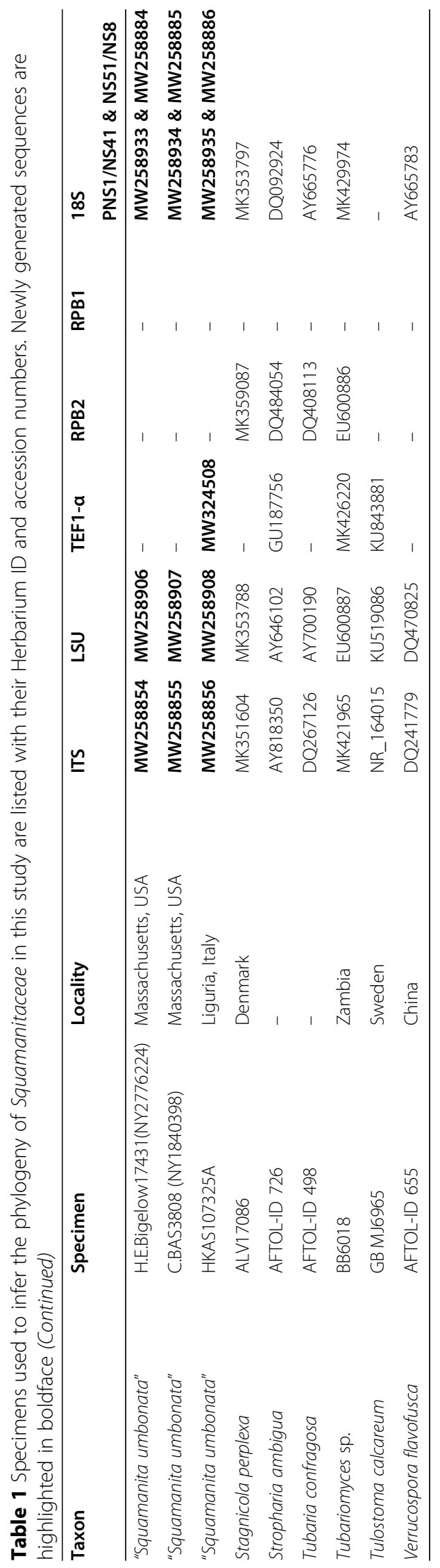


Table 2 Specimens used to identify the mycocecidia of new species of Squamanita in this study are listed with their Herbarium ID and accession numbers. Newly generated sequences are highlighted in boldface

\begin{tabular}{|c|c|c|c|c|c|}
\hline Taxon & Specimen & Locality & ITS & LSU & TEF1- $a$ \\
\hline Amanita aff. excelsa & HKAS107325B & Italy & $\begin{array}{l}\text { MW258872 } \\
\text { MW258873 }\end{array}$ & MW258922 & - \\
\hline "A. aff. hemibapha" & TRTC161164 & Viet Nam & - & KF877244 & KF877133 \\
\hline "A. aff. hemibapha" & TRTC161171 & Viet Nam & - & KF877245 & KF877134 \\
\hline "A. aff. hemibapha" & BPI HPUB 560 & India & - & KF877234 & KF877125 \\
\hline "A. aff. javanica" & HKAS56957 & China & JX998039 & JX998068 & JX998017 \\
\hline "A. aff. javanica" & HKAS56863 & China & JX998040 & JX998071 & JX998014 \\
\hline "A. aff. javanica" & HKAS53281 & China & JX998041 & JX998070 & JX998016 \\
\hline A. aff. sepiacea sp. 1 & HKAS107306B & China & MW258871 & - & MW324505 \\
\hline A. aff. sepiacea sp. 2 & HKAS74861 & China & MW258869 & - & - \\
\hline A. aff. sepiacea sp. 2 & HKAS74862B & China & MW258870 & - & - \\
\hline A. arkansana & RET-354-9 & USA & JX844674 & KF877197 & KP724414 \\
\hline A. brunneolimbata & HKAS78459 & China & MH508274 & - & - \\
\hline A. brunneolimbata & HKAS101392 & China & MH508272 & - & - \\
\hline A. brunneolimbata & HKAS78460 & China & MH508275 & - & - \\
\hline A. caesarea & RET-4271-1 & Italy & JX844685 & KF877207 & KF877106 \\
\hline A. caesaroides & RET-356-10 & China & - & KF877209 & KF877107 \\
\hline A. cinnamomescens (isotype) & RET-290-5 & Pakistan & JX844699 & KF877221 & KF877114 \\
\hline A. citrina & HKAS53467 & Germany & MH508312 & - & - \\
\hline A. cochiseana nom. prov. & RET-498-1 & USA & JX844705 & KF877226 & KP724516 \\
\hline A. fritillaria & HKAS100521 & China & MH508360 & - & - \\
\hline A. fritillaria & HKAS100520 & China & MH508359 & - & - \\
\hline A. garabitoana (paratype) & RET-333-6 & Costa Rica & JX844711 & KF877231 & KF877122 \\
\hline A. hemibapha & RE-342-8 & India & JX844716 & KF877233 & KF877124 \\
\hline A. jacksonii & RET-393-7 & USA & JX844724 & KF877252 & KP724554 \\
\hline "A. javanica" & S-170 & Japan & LC056770 & LC056748 & - \\
\hline "A. javanica" & S-329 & Japan & LC056772 & - & LC164656 \\
\hline "A. javanica" & S-76 & Japan & AB750726 & LC164652 & LC164654 \\
\hline A. kitamagotake & HKAS100824 & China & MW258866 & MW258918 & MW324492 \\
\hline A. kitamagotake & HKAS100825 & China & MW258867 & MW258919 & MW324493 \\
\hline A. kitamagotake & HKAS107309B & China & MW258874 & MW258921 & MW324495 \\
\hline A. kitamagotake & HKAS100826B & China & MW258868 & MW258920 & MW324494 \\
\hline A. kitamagotake (ex-holotype) & EN-4 & Japan & AB721450 & AB721450 & LC164658 \\
\hline A. porphyria & HKAS92088 & China & MH508506 & - & - \\
\hline A. porphyria & MB-100156 & Germany & MH508507 & - & - \\
\hline A. rubromarginata (isotype) & RET-383-1 & Japan & JX844739 & KF877279 & KF877164 \\
\hline A. sepiacea & HKAS80970 & China & MH508589 & - & - \\
\hline A. sepiacea & HKAS79669 & China & MH508588 & - & - \\
\hline A. sepiacea & HKAS74750 & China & MH508587 & - & - \\
\hline A. sepiacea & HKAS70045 & China & MH508586 & - & - \\
\hline A. sepiacea & HKAS68614 & China & MH508585 & - & - \\
\hline A. sepiacea & HKAS56799 & China & MH508584 & - & - \\
\hline A. sepiacea & HKAS100604 & China & MH508582 & - & - \\
\hline A. sinocitrina & HKAS100530 & China & MH508598 & - & - \\
\hline
\end{tabular}


Table 2 Specimens used to identify the mycocecidia of new species of Squamanita in this study are listed with their Herbarium ID and accession numbers. Newly generated sequences are highlighted in boldface (Continued)

\begin{tabular}{llllll}
\hline Taxon & Specimen & Locality & ITS & LSU & TEF1-a \\
\hline A. sinocitrina & HKAS83445 & China & MH508601 & - & - \\
A. sinocitrina & HKAS100531 & China & MH508599 & - & - \\
A. vernicoccora (paratype) & 7020 & USA & GQ250401 & GQ250416 \\
\hline
\end{tabular}

(Spin-column) (Bioteke, China), and then cloned using pClone007 simple vector kit (Tsingke, Beijing). For the recently collected specimen (HKAS100826) and the volval remnants like structure on the cap of a Squamanita specimen (HKAS74862A), 10 clones of each ITS and nrLSU PCR products of each sampling point were randomly selected from a $90 \mathrm{~mm}$ petri dish for sequencing with primer pair M13-47/M13-48 to investigate the mycelium distribution of hosts and parasitising fungi. The cloning, PCR amplification and sequencing followed the protocols described by Cai et al. (2016) and Cui et al. (2018).

\section{Results of sequencing}

For specimen of HKAS100826, the ITS and nrLSU sequences were successfully amplified from all eleven sampling points $(\mathrm{C} 1-\mathrm{C} 5, \mathrm{~B} 1-\mathrm{B} 6)$. Among them, there are two bands occurring in gel electrophoresis diagram of each of the PCR products of ITS from six sampling points of mycocecidium (B1, B2, B3, B4, B5, B6), see Fig. 1. By cloning and sequencing all of the purified PCR products of ITS and nrLSU, a total of 50 ITS and 50 nrLSU sequences were generated from all points (C1-C5). After alignment and comparison, all of them belong to the same species, namely the mycoparasitic species itself. For the mycocecidium, each band of PCR productions with two bands were excised from gel respectively, and then purified and sequenced, generating a total of 120 ITS and 60 nrLSU sequences from sampling points B1-B6. After analysis, two types of mushroom sequences were detected for each DNA locus. Statistically, 50\% ITS, 90\% nrLSU matched to the potential mycoparasitic species and 50\% ITS, 10\% nrLSU belong to the potential host species. For the volval remnants on the cap of the Squamanita specimen (HKAS74862A), 60\% ITS, $90 \%$ nrLSU were the potential mycoparasitic species and 20\% ITS, 0\% nrLSU were assigned to the potential host species, others are Trichoderma hirsutum or vector sequences. For the other specimens of Squamanita and nearby Amanita, all sequences were amplified then directly sequenced or obtained by cloning from PCR products. One hundred forty-five sequences have been submitted to GenBank and used for phylogenetic analyses (Tables 1 and 2). The sequences of the two potential species of hosts are the same as those of the coexisting Amanita species respectively, and were finally identified to belong to A. kitamagotake (Fig. 4) and the A. sepiacea complex (Fig. 5). The potential mycoparasitic species are clustered into the genus Squamanita (Figs. 2 and 3).

\section{DNA sequence alignment}

Sequences used in study are listed in Tables 1 and 2 with their Herbarium ID and accession numbers. Four
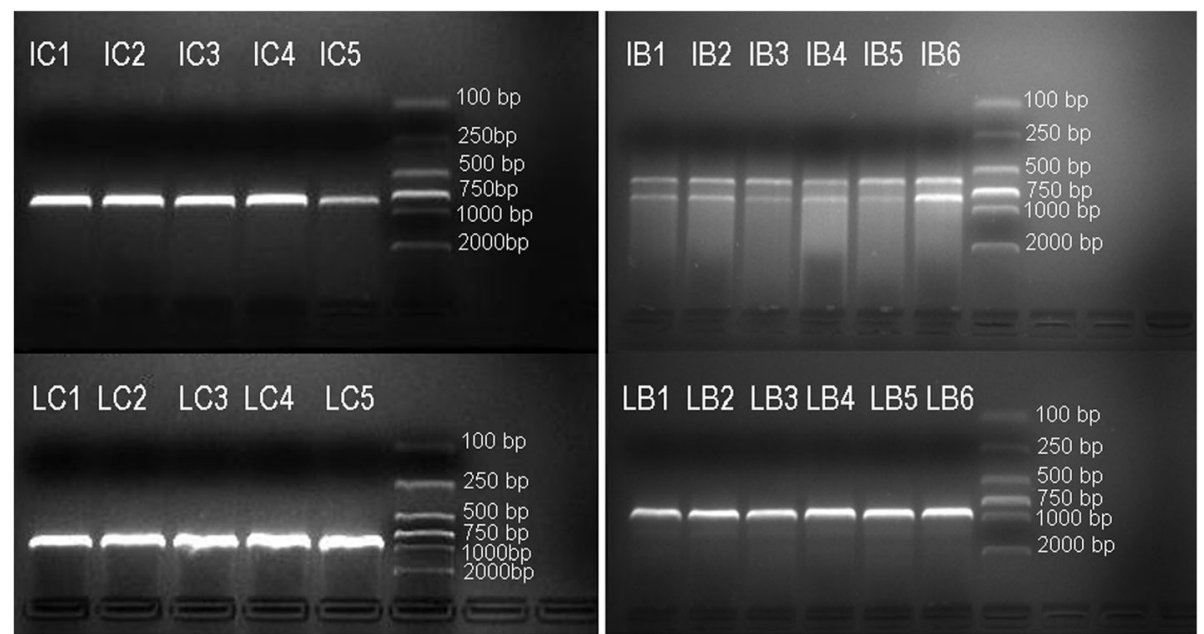

Fig. 1 Gel electrophoresis diagram of the PCR products amplified from 11 sampling points on the basidiome $(C 1, C 2, C 3, C 4, C 5)$ and mycocecidium (B1, B2, B3, B4, B5, B6) of Squamanita mira (HKAS100826, holotype), as indicated on Fig. 6. I and L indicate ITS and LSU ( $\mathrm{nrLSU})$, respectively 


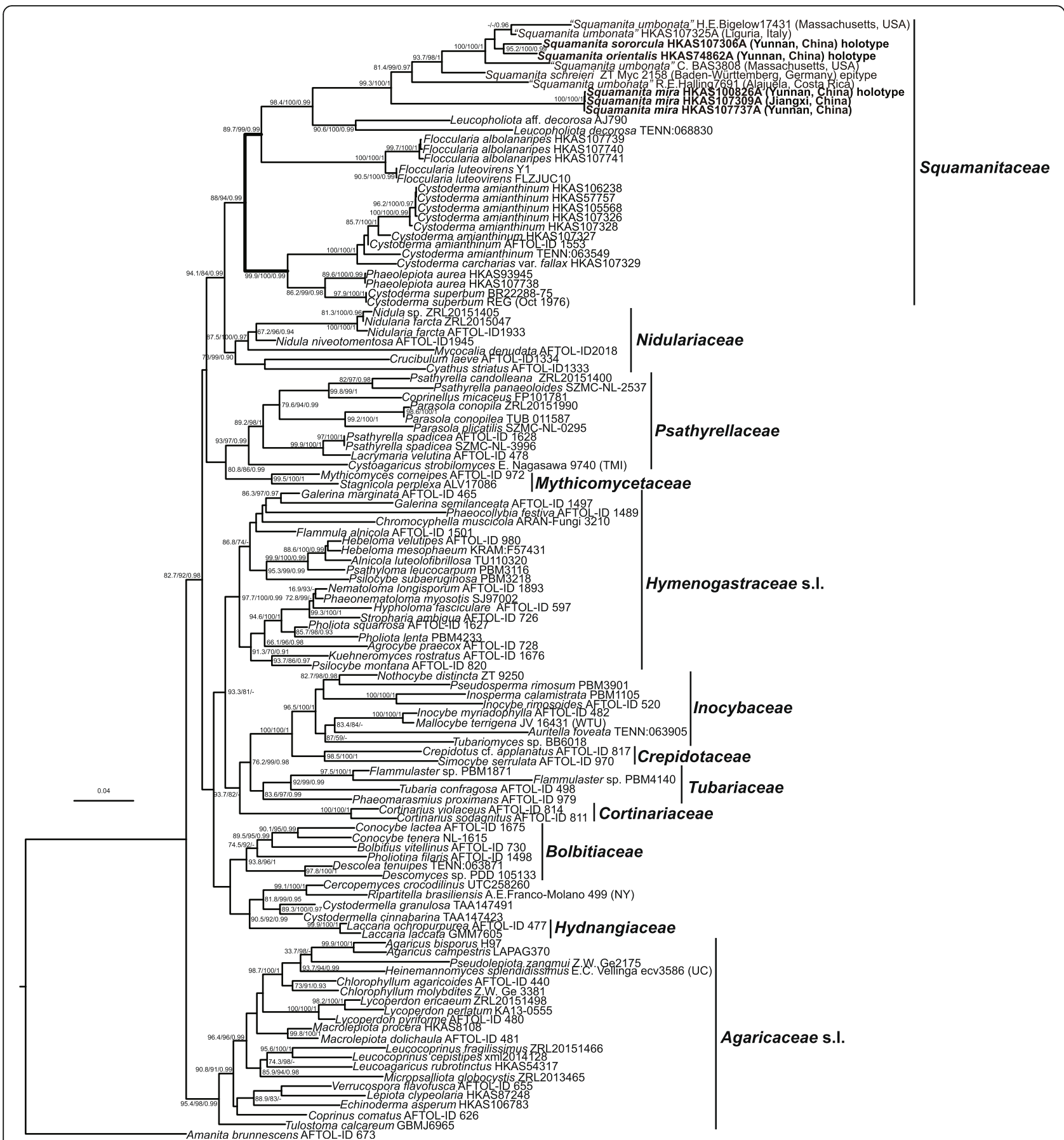

Fig. 2 Maximum-Likelihood (ML) phylogenetic tree of Squamanitaceae inferred from the 18S-5.8S-nrLSU-RPB2-TEF1-a dataset, with SH-aLRT (left), ultrafast bootstrap (UFB) (middle), and PPs values (right) near by the corresponding node. Only one of SH-aLRT $>80$ or UFB $>95$ for ML and PPS $>0.90$ for Bl are indicated along branches (SH-aLRT/UFB/PP). New species Squamanita mira, S. orientalis, S. sororcula are highlighted in boldface

datasets, namely 18S-5.8S-nrLSU-RPB2-TEF1- $\alpha$, 18SITS-nrLSU-RPB2-TEF1- $\alpha$, ITS-nrLSU-TEF1- $\alpha$, and ITS were used in our study to reinvestigate the phylogeny of Squamanitaceae, identify the phylogenetic position of the basidiomes and mycocecidia of the mycoparasitic species. From the first dataset to the last, a total of 4100 ,
4743, 1878 and 693 characters were used in the phylogenetic analyses, respectively. Moreover, two phylogenetic trees which only use ITS and nrLSU sequences were used to investigate the phylogeny of Squamanitaceae are provided as additional files (Additional files 1 and 2), respectively. The final alignments have been submitted to 


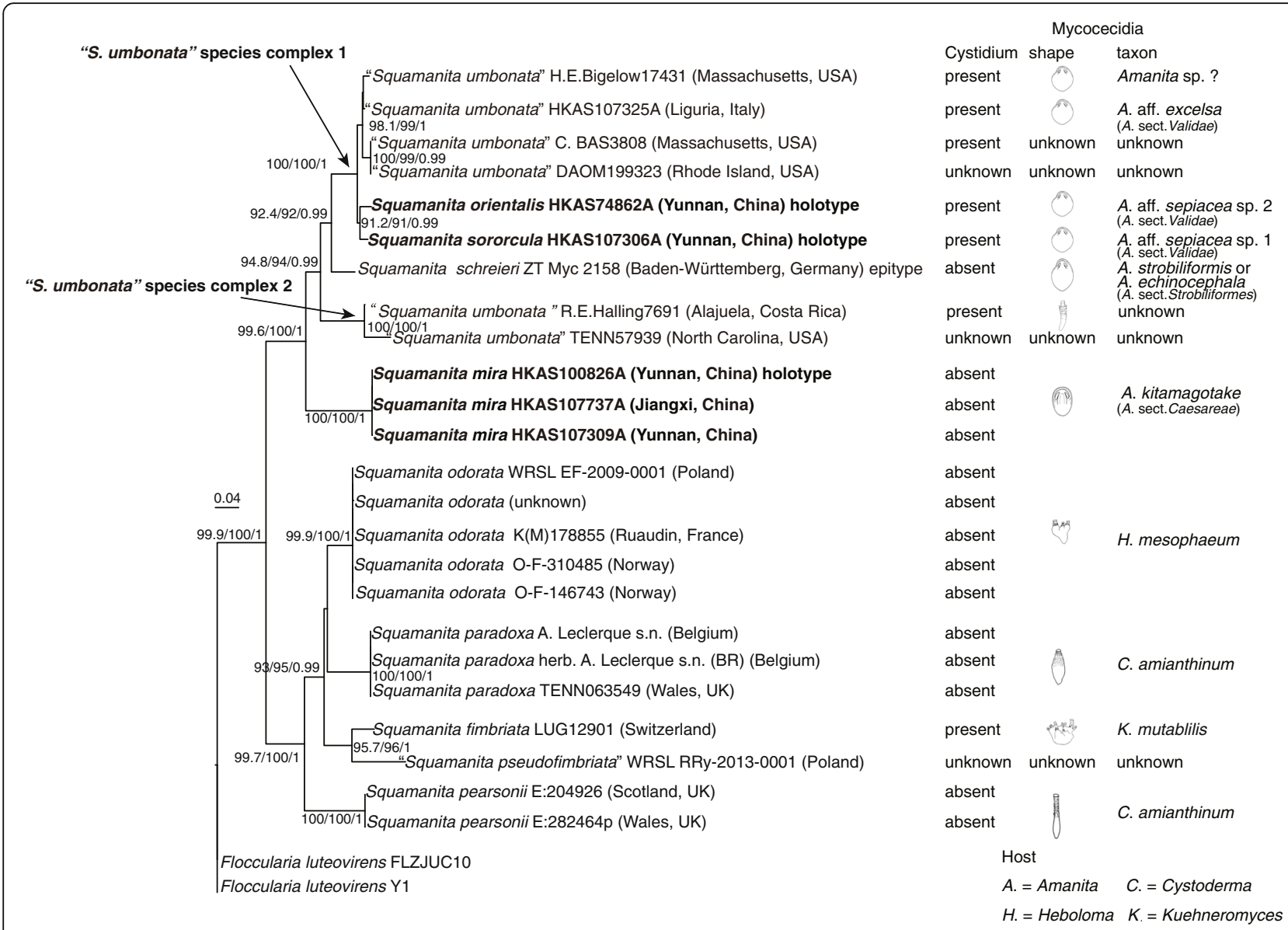

Fig. 3 Maximum-Likelihood (ML) phylogenetic tree of Squamanita inferred from the 18S-ITS-nrLSU-RPB2-TEF1-a dataset, with SH-aLRT (left), ultrafast bootstrap (UFB) (middle), and PPs values (right) near by the corresponding node. Only one of SH-aLRT $>80$ or UFB $>95$ for ML and PPs $>0.90$ for Bl are indicated along branches (SH-aLRT/UFB/PP). Cystidium present or absent, and the shape and taxon of mycocecidia of counterpart Squamanita species are shown. New species Squamanita mira, S. orientalis, S. sororcula are highlighted in boldface

TreeBase (https://www.treebase.org/, nos.: 27,493, 27, 494, 27,496, 27,497, 27,498, 27,499).

For each dataset, the sequences were aligned using MAFFT v6.8 (Katoh et al. 2005), manually edited with BioEdit v7.0.9 (Hall 1999) and concatenated with Phyutility v2.2.1 (Smith and Dunn 2008). Unsampled gene regions were coded as missing data. In the concatenated datasets, all introns of RPB2 and TEF1- $\alpha$ were excluded because of the difficulty in alignment. Maximum likelihood (ML) analyses were performed using IQ-TREE 1.6 (Trifinopoulos et al. 2016). Bayesian Inference (BI) analyses were used to analyze the datasets with MrBayes v3.1.6 (Ronquist et al. 2012). The optimal substitution models for each dataset were determined by using the Akaike Information Criterion (AIC) implemented in MrModeltest v2.4 (Nylander 2004), with 18S, 5.8S/ITS and nrLSU treated as a single block. In ML analyses, the substitution model options for four datasets were auto evaluated after provided partition file by using IQ-TREE 1.6 (http://iqtree.cibiv.univie.ac.at/), clade support for the ML analyses was assessed using an $\mathrm{SH}$-aLRT test with 1000 replicates (Guindon et al. 2010) and 1000 replicates of the ultrafast bootstrap (UFB) (Hoang et al. 2018). In the ML analyses, nodes with support values of both SH-aLRT $\geq 80$ and UFB $\geq 95$ were considered well supported, nodes with one of SH-aLRT $\geq 80$ or UFB $\geq 95$ were weakly supported, and nodes with both SH-aLRT $<80$ and UFB $<95$ were unsupported, and the other parameters use the default settings. For BI analyses, the selected models for four datasets were 18S-5.8S$\operatorname{nrLSU}(\mathrm{GTR}+\mathrm{I}+\mathrm{G})-\mathrm{RPB} 2(\mathrm{GTR}+\mathrm{I}+\mathrm{G})-\mathrm{TEF} 1-\alpha(\mathrm{GTR}+$ $\mathrm{I}+\mathrm{G}), \quad$ 18S-ITS-nrLSU(GTR + I + G)-RPB2(SYM + I) $\operatorname{TEF} 1-\alpha(S Y M+I+G), \quad \operatorname{ITS}(S Y M+G)-\operatorname{nrLSU}(H K Y+I)-$ TEF1 $-\alpha(S Y M+G)$, and ITS $(G T R+G)$ respectively. Bayesian analyses used the selected models and four chains were run simultaneously for 2 million generations with trees sampled every 100 generations. The sampling of the posterior distribution was considered to be adequate when the average standard deviation of split frequencies was lower than 0.01 . Chain convergence was 
determined by checking the effective sampling size (ESS $>200$ ) in Tracer v. 1.5 (Rambaut and Drummond 2009). Nodes with Bayesian posterior probability $(\mathrm{PP})>0.90$ were considered well supported. Subsequently, trees are summarized and posterior probabilities were obtained by using the sumt and sump command implemented in MrBayes by discarding the first $25 \%$ generations as burn-ins.

\section{RESULTS}

For the four datasets, topologies of the phylogenetic trees generated from ML and BI analyses are nearly identical with minimal variation in statistical support values, and thus only the trees inferred from the ML analyses are displayed. The tree generated from the 18S-5.8S-nrLSU-RPB2-TEF1- $\alpha$ dataset reveals that Squamanita, Cystoderma, Phaeolepiota, Floccularia, and Leucopholiota form a monophyletic clade with weakly statistical support in ML analysis but with strong statistical support in BI analysis (SH-aLRT/UFB/PP $=88 / 94 /$ 0.99), Squamanita and Leucopholiota are sister groups of Floccularia (SH-aLRT/UFB/PP = 98.4/100/0.99), Phaeolepiota nested within Cystoderma (SH-aLRT/UFB/PP = 99.9/100/0.99), and Squamanita is a monophyletic group with strong statistic support in both of ML and BI analyses (SH-aLRT/UFB/PP = 99.3/100/1) (Fig. 2). Taking the study of Matheny and Griffith (2010) and Kalichman et al. (2020) into consideration, the family Squamanitaceae is formally emended to accommodate the above-mentioned five genera. Besides, both trees generated from 18S-5.8SnrLSU-RPB2-TEF1- $\alpha$ and 18S-ITS-nrLSU-RPB2-TEF1- $\alpha$ datasets reveal that the three potential Squamanita species from China are novel (Figs. 2 and 3). They are described below as S. mira, S. orientalis and S. sororcula, respectively. The tree generated from the 18S-ITS-nrLSU-RPB2TEF1- $\alpha$ dataset also shows that several "S. umbonata" from North America, Europe and East Asia harbor a complex of species, with six subclades in the phylogenetic tree (Fig. 3), and one "S. umbonata" from Central America harbors a monophyletic clade with a sequence from North Carolina, USA (Fig. 3). The trees generated from ITSnrLSU-TEF1- $\alpha$ and ITS datasets reveal that the host of $S$. mira is A. kitamagotake (Fig. 4), and those of S. orientalis and $S$. sororcula are species of the A. sepiacea complex (Fig. 5).

\section{TAXONOMY}

Squamanitaceae Jülich, Biblthca Mycol. 85: 390 (1981).

Type: Squamanita Imbach, Mitt. Naturf. Ges. Luzern 15: 81 (1946).

Synonym: Cystodermataceae Locq., Mycol. gén. struct: 108 (1984); nom. inval. (Art. 36.1, lacking a Latin diagnosis or reference to a previously published Latin diagnosis).
Emended description: Basidiome lepiotoid to tricholomatoid, small to medium-sized, with pileus and central stipe; lamellae adnexed to adnate, or with decurrent tooth, never free. Stipe with or without annulus. Mycocecidia subglobose or subcylindrical to clavate fusiform. Stipe and pileus often with a floccose layer composed of loose sphaerocysts. Hyphal system monomitic. Hyphae cylindrical or slightly inflated, thin-walled, smooth, with clamps. Cystidia absent or present; if present, thin- to slightly thick-walled, smooth. Basidia narrowly clavate, 4spored. Basidiospores subglobose to ellipsoid or subreniform, rarely angular, thin- to slightly thick-walled, colorless, yellowish or brownish mostly smooth, in some taxa finely verrucose to finely echinulate, without germ pore, amyloid or inamyloid, not or slightly dextrinoid. Conidia present or absent, if present, globose, subglobose, ovoid, irregularly clavate, cylindrical, ellipsoid, broadly fusiform or fusiform, 7-16 $(-19) \times 4-7.5(-12.5) \mu \mathrm{m}$, with clamps when young, later more or less bifid at base, colourless to pale brownish yellow, smooth or ornamented, with thickened wall, development of conidia basifugal. Conidiophores colourless, septate when young, thin walled, densely branching, 4-6 $\mu \mathrm{m}$ wide, with clamps, the older conidia-bearing branches non-septate, sickle-shaped. Chlamydospores present or absent, if present, obovoid, clavate, rarely ventricose-fusiform, rectangular to variously shaped, inamyloid, colorless to yellowish, thick-walled.

Substrate: On soil, wood or parasitizing agarics.

Genera included: Squamanita, Cystoderma, Phaeolepiota, Leucopholiota, and Floccularia.

Notes: Here we fix the application of the generic name Squamanita by lecto- and epitypfiying the type species of the genus, $S$. schreieri, and describe the new species discovered in this study.

Squamanita schreieri Imbach, Mitt. Naturf. Ges. Luzern 15: 81 (1946).

Type: Imbach, Mitt. Naturf. Ges. Luzern 15: 80 [unnumbered plate] (1946) -lectotype designated here (MBT 394854). Germany: Baden-Württemberg, Taubergiessen Nature Reserve, Alluvial forest, close to a Populus tree, 10 Oct 1991, Leg. M. Wilhelm (no. 295) ZT Myc 2158 - epitype designated here (MBT 394983).

Notes: The original description cited the following collections: "Schreier, 17 Jul. 1935; Schreier, 4 Aug. 1936; Schreier, 8 Aug. 1937; Arndt, 11 Jul. 1942; Haller, 17 Oct. 1943; Furrer, Schlapfer \& Imbach, 18 Jul. 1944; Rohl-Wütherich, Aarau \& Imbach, 31 Jul. 1945”. None of these original collections could be located in G, and the only remaining original material is the illustration provided by Imbach which is therefore designated as lectotype here. As a specimen is essential to fix the application of the name, we designate as an epitype a modern collection in Eidgenössische Technische Hochschule Zürich which fits the original diagnosis and plate. 


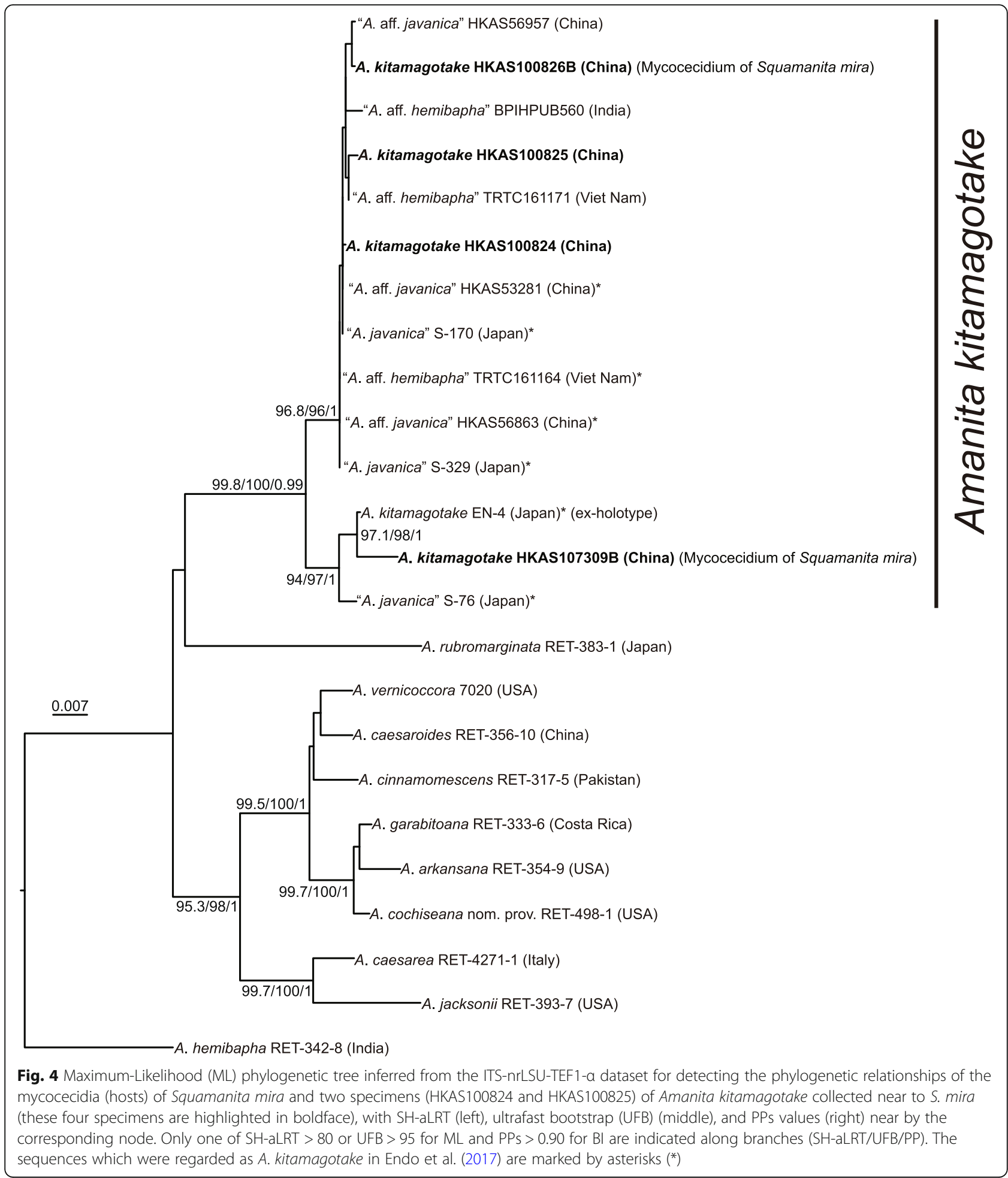

Squamanita mira J. W. Liu \& Zhu L. Yang, sp. nov. - Fungal Names FN570781;

MycoBank 836,584. (Figs. 6 and 7).

Etymology: - mirus (Lat.), wonderful or extraordinary, referring to the wonderful basidiome.
Diagnosis: S. mira differs from other species of the genus by the mycocecidia which have a limbate volvalike structure and the absence of cystidia.

Type: China: Yunnan Province: Ailaoshan Natural Reserve, Chuxiong, Nanhua, in the forests dominated by 


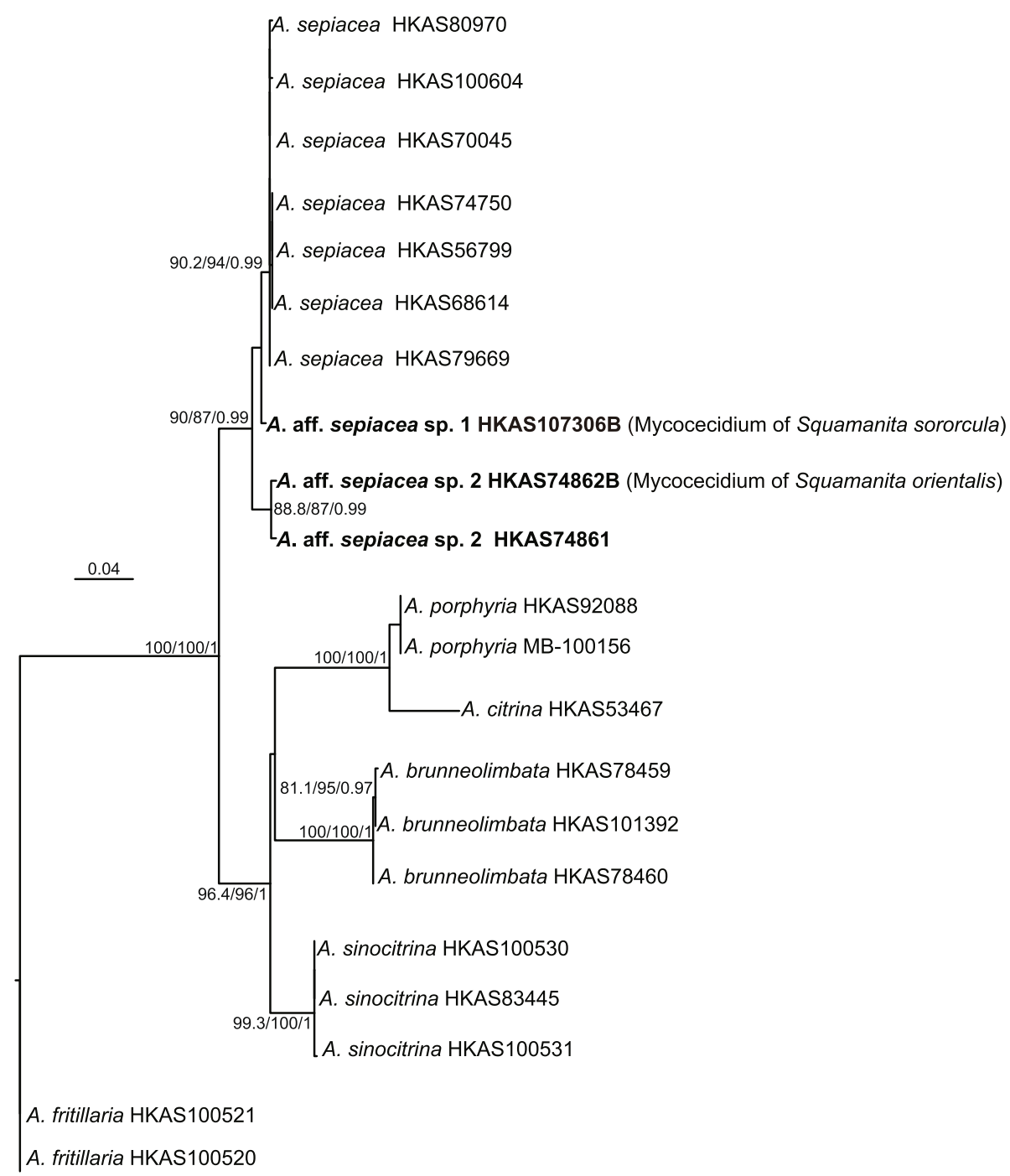

Fig. 5 Maximum-Likelihood (ML) phylogenetic tree inferred from the ITS dataset for detecting the phylogenetic relationships of the mycocecidia (hosts) of Squamanita orientalis, S. sororcula and one specimen (HKAS74861) of Amanita sepiacea that was collected nearby S. orientalis (these three specimens are highlighted in boldface), with SH-aLRT (left), ultrafast bootstrap (UFB) (middle), and PPs values (right) near by the corresponding node. Only one of SH-aLRT $>80$ or UFB $>95$ for ML and PPs $>0.90$ for Bl are indicated along branches (SH-aLRT/UFB/PP)

Fagaceae and Pinaceae, 24⒌'27.53"N, 10049'14.91 "E, $2235 \mathrm{~m}$ elev., 10 Aug. 2017, J. W. Liu 904 (HKAS100826A - holotype; GenBank Acc. nos.: 18S = MW258926 \& MW258878, ITS $=$ MW258847, nrLSU = MW258899, TEF1- $\alpha=$ MW324489, RPB2 = MW289796).

Description: Pileus ca. $40 \mathrm{~mm}$ diam, subconical to convex, distinctly umbonate; surface dry, yellowish brown (6C6-7) or honey-yellow (6C6-8), or viscid if moist, covered with dark orange (6A8), yellow-tawny (6B7-8) or honey yellow (6C6-8), repent, fibrillose squamules; margin incurved, strongly appendiculate, irregularly and densely corniform and fibriform squamules derived from breaking up of the veil, and slightly paler than the pileus surface. Lamellae adnexed to adnate, moderately crowded, narrow; edge irregularly serrate-dentate or subundulate. Stipe 43-46 × 12-24 mm, subcylindrical, densely covered with brown (6A7-8), tawny yellow (6B7-8) to yellowish brown (5A6-8), appressed or recurved fibrillose and villiform squamules, at the upper part of the stipe covered with fluffy and villose, brown (5A6-8), tawny yellow (6B7-8) to yellowish brown (6C6-7) appressed or erect, fibrillose or obliquely lacerate scales arranged in irregular rings, 4-6 mm from apex, extreme apex off-white (1A1-2) and subglabrous. Mycocecidia subglobose to napiform, 40-46 × 5-16 mm, nearly smooth, whitish (1A1) or locally yellow (6A4-5) on external surface; Volval limb arising from margin of mycocecidia, 6-20 mm tall; context of pileus and stipe 


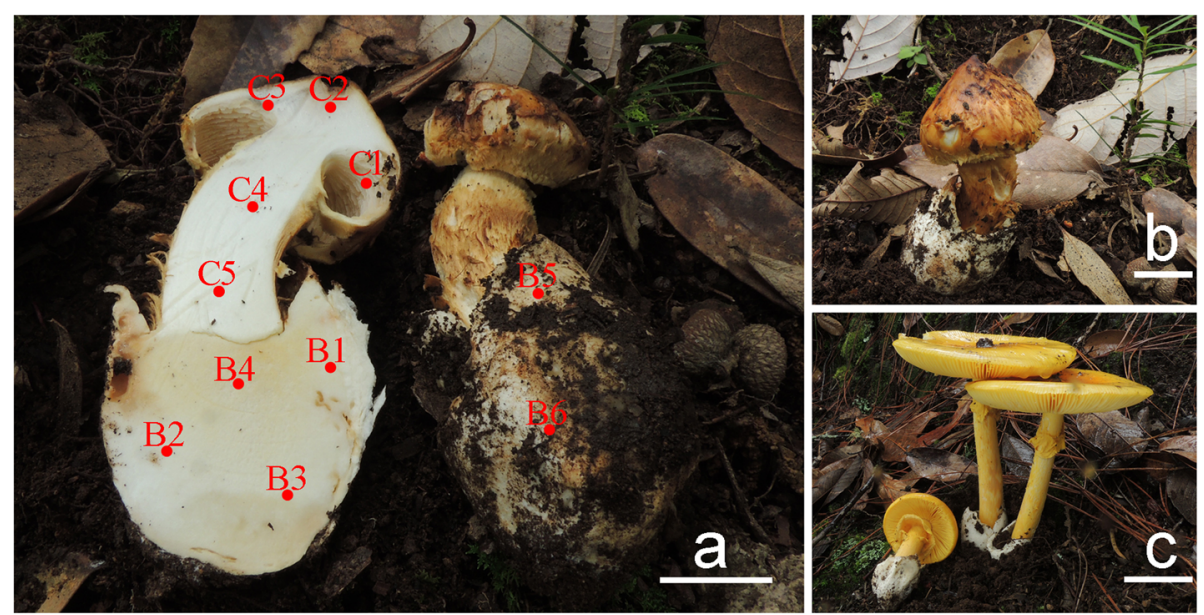

Fig. 6 a-b Basidiomes of Squamanita mira HKAS100826 (holotype) photos by Jian-Wei Liu. Bars: 20 mm. c Basidiomes of Amanita kitamagotake. HKAS100825. Photos by Jian-Wei Liu. Bars: 50 mm. Sampling points are marked by red dots labelled C1, C2, C3, C4, C5, (from basidiome) and B1, B2, B3, B4, B5, B6 (from mycocecidium)

white (1A1), with a strong aromatic smell, like that of Tricholoma matsutake; context of mycocecidia white, unchanging on exposure, odour not distinctive.

Basidiospores [60/1/1] (5.5-) 6-7 (-7.5) ×4-5 (6) $\mu \mathrm{m}$, $(\mathrm{Q}=(1.16) 1.33-1.75(-1.8), \mathrm{Qm}=1.53 \pm 0.13)$, ellipsoid or subreniform, colorless, hyaline, smooth, inamyloid. Basidia 22-65 $\times 9-12 \mu \mathrm{m}$, fusiform to ventricosefusiform, hyaline; sterigmata $4-5 \mu \mathrm{m}$ long; Cystidia absent. Subhymenium 10-20 $\mu \mathrm{m}$ thick, composed of 4$7 \mu \mathrm{m}$ wide filamentous hyphal segments. Lamellar trama regular, composed of colorless, thin-walled hyphae 4$17 \mu \mathrm{m}$ diam, branching, sometimes anastomosing. Pileipellis a cutis with transition to a trichoderm at regular intervals, composed of loosely and more or less radially arranged, thin-walled hyphae 90-200 $(-370) \times 5-20 \mu \mathrm{m}$, and upper part of pileipellis often with fine brownish granular incrustations and yellowish to brownish filamentous hyphae, constricted at septa; Mycocecidia composed of abundant ovoid to subglobose inflated cells, and filamentous hyphae similar to those on the pileus, clamp connections present; chlamydospores not observed.

Ecology: Parasitic on Amanita kitamagotake (HKAS100826B, GenBank Acc. nos.: ITS = MW258868, nrLSU $=$ MW258920, $\quad$ TEF1 $\alpha=$ MW324494; HKAS107309B, GenBank Acc. nos.: ITS $=$ MW258874, nrLSU $=$ MW258921, TEF1- $\alpha=$ MW324495) growing on soil under trees of Fagaceae and Pinaceae.

Distribution: Currently known from Jiangxi and Yunnan Province, central and Southwest China.

Notes: In this study, molecular evidence confirms that the hosts of S. mira as well as two collections of Amanita in the nearby area, within $2 \mathrm{~km}$ of $S$. mira, are $A$. kitamagotake (Figs. 4, 6).

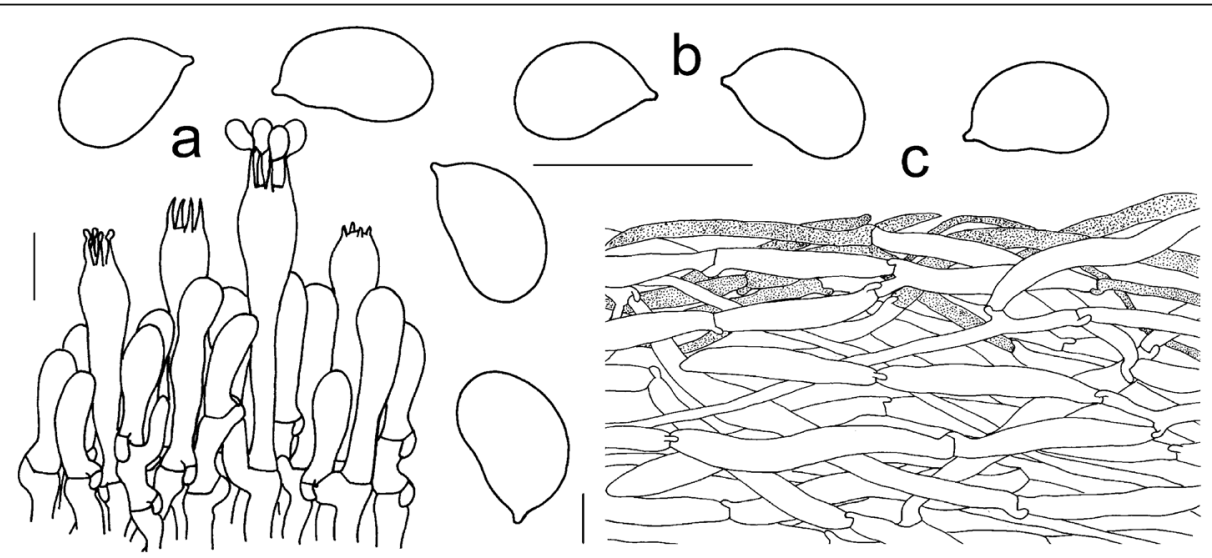

Fig. 7 Microscopic features of Squamanita mira (HKAS100826A, holotype). a Hymenium and subhymenium. b Basidiospores. c Pileipellis section. Bars $=10 \mu \mathrm{m}$. Drawings by Jian-Wei Liu 
Morphologically, S. mira highly resembles the informally published "S. tropica" ("nom. Prov.") (Bas 1965), because both are parasitic on basidiomes of Amanita and form a volva-like structure at the base of the stipe. Furthermore, they share abundant tawny squamules on the pileus surface, serrate-dentate or subundulate lamellae edges, irregular ring analogues on the upper part of the stipe and ellipsoid to subreniform basidiospores. However, S. mira differs from S. tropica in its subconical to convex pileus with a distinct umbo. The material of $S$. tropica is lost (Bas 1965).

Squamanita mira is also more or less similar to $S$. schreieri and the specimens under the two species complexes of "S. umbonata" from all over the world in some morphological features. However, S. mira can be distinguished from the aforementioned taxa by its mycocecidia with a limbate volva-like structure and absence of cystidia. Phylogenetically, they are grouped, however, in different clades (Figs. 2 and 3).

Additional specimens examined: China: Jiangxi Province: Jian, Jinggangshan City, Jinggangshan scenic spots, 800$900 \mathrm{~m}$ elev. 19 July. 2019, Chunlei Pan JGSO01 (HKAS107309A, GenBank Acc. nos.: 18S = MW258927 \& MW258879, ITS $=$ MW258848, $\quad$ nrLSU $=$ MW258900, TEF1- $\alpha=$ MW324490, RPB2 = MW289797). Yunnan Province: Ailaoshan Natural Reserve, Chuxiong, Nanhua, in the forests dominated by Fagaceae and Pinaceae, 24.53'46.23" N, 100 48'11.14"E, $2339 \mathrm{~m}$ elev., 11 Aug. 2020, LCCOO2 (HKAS107737A, GenBank Acc. nos.: 18S = MW258928 \&
MW258880, $\quad$ ITS $=$ MW258849, $\quad \operatorname{nrLSU}=$ MW258901, TEF1- $\alpha=$ MW324491, RPB2 = MW289798).

Squamanita orientalis J. W. Liu \& Zhu L. Yang, sp. nov. - Fungal Names FN570782;

MycoBank 836585. (Figs. 8, 9 and 10).

Etymology: -orientalis (Lat.): from the East.

Diagnosis: S. orientalis differs from other species by its irregular fibrillose annular zone on the upper part of the stipe and ciliate squamules on the pileal margin, larger cystidia (90-105 × 17-27 $\mu \mathrm{m})$, and subglobose mycocecidia.

Type: China: Yunnan Province: Laowopo dunk, Chongren, Nujiang, 1700-1800 m elev., in forest dominated by Fagaceae and Rhododendron, 7 Aug. 2011, Gang Wu 548 (HKAS74862A - holotype; GenBank Acc. nos.: $18 \mathrm{~S}=\mathrm{MW} 258930 \quad \& \quad \mathrm{MW} 258881, \quad$ ITS $=$ MW258851, nrLSU $=$ MW258903, TEF1 $\alpha=$ MW324509, $\quad$ RPB2 = MW289799).

Description: Pileus ca. $40 \mathrm{~mm}$ diam, subconical to convex; surface dry, covered with yellowish brown (6C6-7), light brown (6D4-5) to dark brown (6E5) or dark grey (6E1-3), more or less radially arranged, repent, fibrillose squamules; margin with ciliate squamules derived from breaking up of the veil, and the color is slightly lighter than surface of pileus; volval remnants of host present on the disc, grey. Lamellae white (1A1), adnexed to adnate, moderately crowded, denticulate. Stipe $30 \times 6-10$ $\mathrm{mm}$, nearly cylindric, usually tapering upward; surface densely covered by squamules arranged in irregular fibrillose annular zone at the upper part of the stipe,
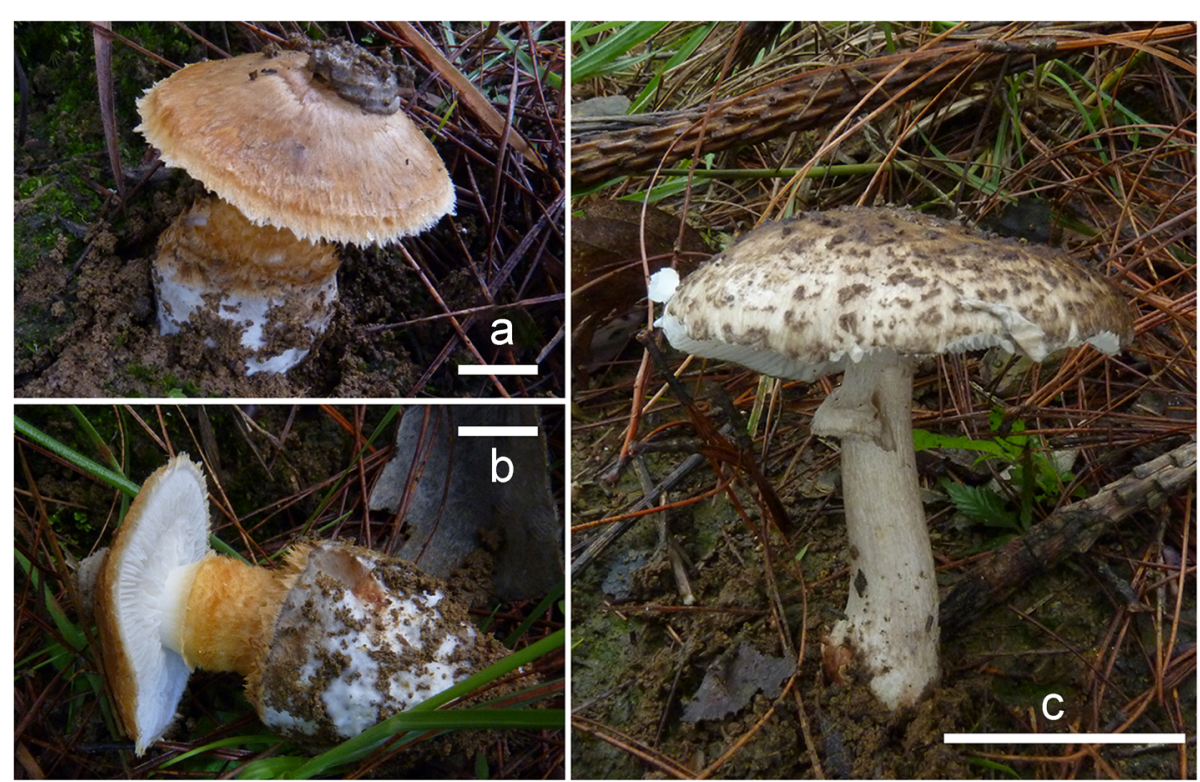

Fig. 8 a-b Basidiomes of Squamanita orientalis (HKAS74862A, holotype). Photos by Gang Wu. Bars: $10 \mathrm{~mm}$. A lump of clay is attached on the center of pileus, and the apical part of volval remnants on mycocecidiium can be observed between clay and pileus under anatomical lens. $\mathbf{c}$ Basidiome of Amanita sepiacea (HKAS74861). Photos by Gang Wu. Bars: 50 mm 


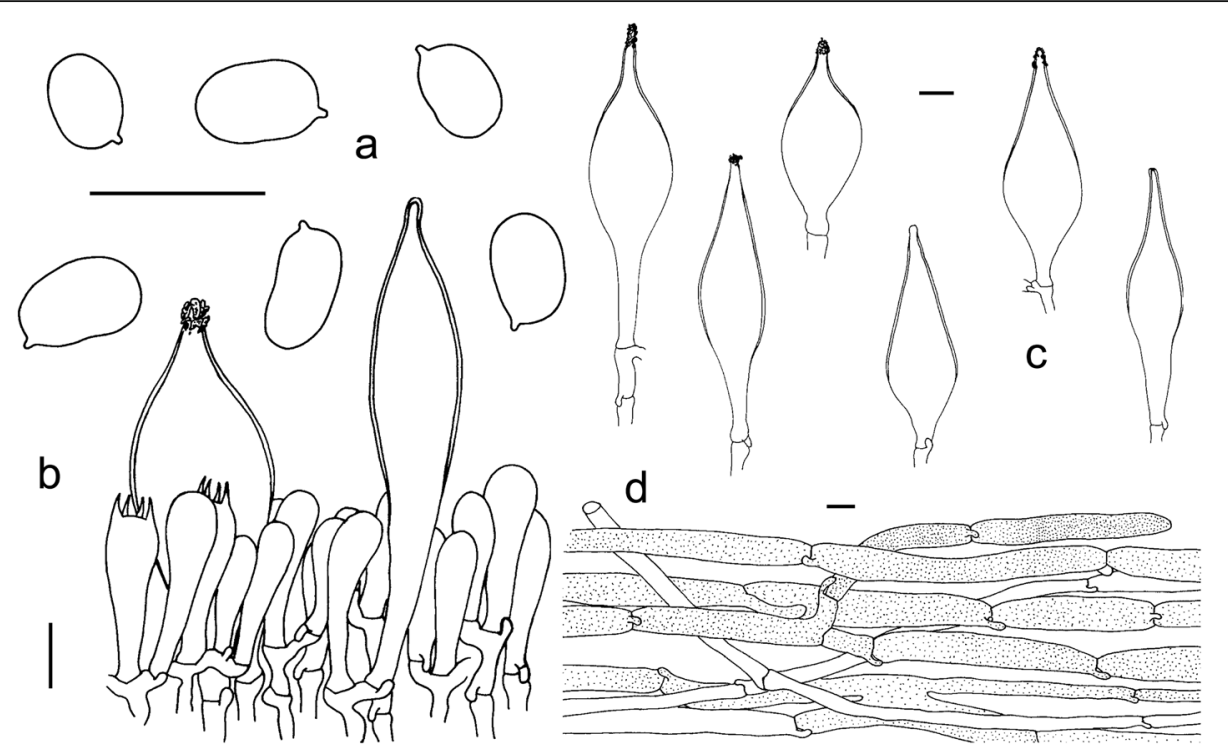

Fig. 9 Microscopic features of Squamanita orientalis (HKAS74862A, holotype). a Basidiospores. b Hymenium and subhymenium with one of the two pleurocystidia covered with refractive incrustations. c Pleurocystidia, four of them covered with refractive incrustations. $\mathbf{d}$ Pileipellis section. Drawings by Jianwei Liu. Bars $=10 \mu \mathrm{m}$

extreme apex white (1A1) and nearly smooth, the part below the ring is covered with orange (6A6-7), tawny yellow (6C7) or yellowish brown (6D7-8) appressed or erect, obliquely lacerate scales. Mycocecidium subglobose $35 \times 20-30 \mathrm{~mm}$, nearly smooth, and whitish or grey spots on external surface. The transitional zone between stem and mycocecidium with some irregular rings of tawny-ochraceous (6B7-8) or dingy brown (6E5) color, fibrillose, appressed, or with erect, obliquely upwardpointing scales or lacerate scales.

Basidiospores [50/1/1] (5-) 5.5-6 (-6.5) × 4-5 (-6) $\mu \mathrm{m}[\mathrm{Q}=(1.2-) 1.5-1.65, \mathrm{Q}=1.43 \pm 0.10]$, broadly ellipsoid, ellipsoid to elongate, sometimes subreniform in side view. Basidia $20-35 \times 5-10 \mu \mathrm{m}$, subclavate, 4spored, fusiform to ventricose-fusiform, hyaline; sterigmata 3-4 $\mu \mathrm{m}$ long; basal septa often with clamps. Cystidia numerous, $90-105 \times 17-27 \mu \mathrm{m}$, fusiform to ventricose-fusiform, with obtuse to acute apex, upper part slightly to moderately thick-walled (up to $1 \mu \mathrm{m}$ diam.), sometimes with refractive incrustations, hyaline. Lamellar trama regular, composed of colorless, thin-walled hyphae 4-15 $\mu \mathrm{m}$ diam, branching, sometimes anastomosing; clamps present and common. Subhymenium 10-15 $\mu \mathrm{m}$ thick, composed of $4-6 \mu \mathrm{m}$ wide filamentous hyphal segments; volval remnants of host on pileus composed of \pm irregularly arranged elements: inflated cells very abundant (to locally dominant), subglobose $(30-50 \times 30-50 \mu \mathrm{m})$ or ovoid to broadly clavate $(30-60 \times 20-30 \mu \mathrm{m})$, solitary and terminal, or in chains of $2-3$ and then terminal, inflated cells sometimes external upset (up to $1 \mu \mathrm{m}$ thick), usually colorless and hyaline, occasionally with brownish vacuolar pigments, and the majority of hyphae without clamp connection; inner part of volval remnants near pileus surface composed of \pm irregularly arranged elements: inflated cells usually brownish to fawn colored, two types of filamentous hyphae in the tissues: either with filamentous hyphae usually colorless and hyaline, $2-6 \mu \mathrm{m}$ wide, without clamp connection; or with hyphae similar to lotus root, $60-150 \times 4-15 \mu \mathrm{m}$, swollen in the middle but constricted at septa, with clamp connection. Mycocecidium composed of abundant ovoid to subglobose inflated cells $(45-110 \times 24-65 \mu \mathrm{m})$ and filamentous hyphae colorless and hyaline, $2-6 \mu \mathrm{m}$ wide, with clamp connections similar to those on the pileus; chlamydospores not observed.

Ecology: Parasitic on Amanita sepiacea (HKAS74862B, GenBank Acc. nos.: ITS = MW258870) growing on soil under trees of Fagaceae and Rhododendron.

Distribution: Currently known from Yunnan Province, Southwest China.

Notes: Our morphological data and molecular phylogenetic evidences confirm that the host of $S$. orientalis and the collection of Amanita in the nearby area within two kilometers' range of $S$. orientalis are $A$. sepiacea (Figs. 5, 8, 10). Interestingly, some volval remnants of $A$. sepiacea are found on the center of the pileal surface of 

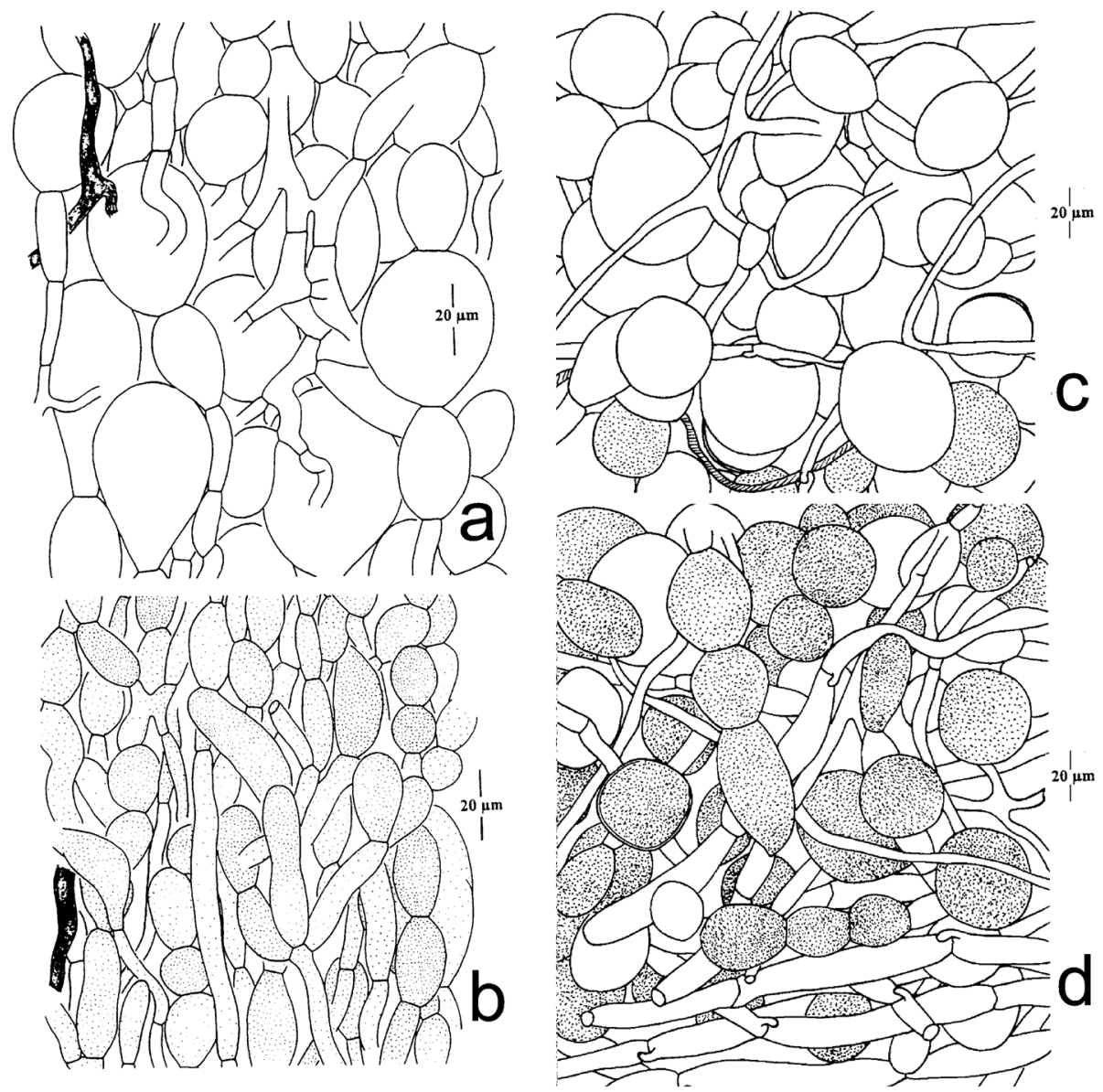

Fig. 10 Microscopic features of volval remnants on the pileus of Amanita sepiacea (HKAS32519) and Squamanita orientalis (HKAS74862A, holotype). $\mathbf{a}$ the upper part of a volval remnant on the pileus of $A$. sepiacea. $\mathbf{b}$ the lower part of a volval remnant on the pileus of $A$. sepiacea. Drawings by Zhuliang Yang (2005). c Upper layer of a volval remnant on the pileus of S. orientalis. d Inner layer of a volval remnant on the pileus of S. orientalis. Drawings by Jianwei Liu. Bars $=20 \mu \mathrm{m}$. Cells with vacuolar pigment and vascular hyphae are dotted and shaded respectively. Hyphae with clamps belong to S. orientalis
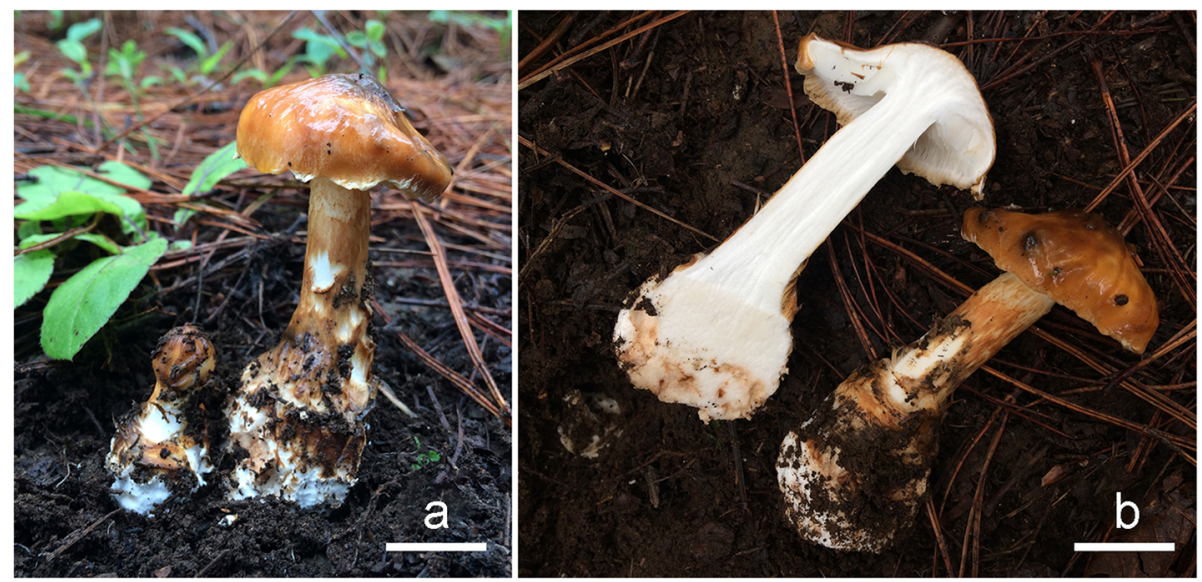

Fig. 11 a-b Basidiomes of Squamanita sororcula (HKAS107306A, holotype). Photos by Fa Li. Bars: 20 mm 
S. orientalis (Fig. 8), and its anatomical features are those of A. sepiacea (Yang 2005) (Fig. 10), and the filamentous hyphae with clamp connection belong to $S$. orientalis (Fig. 10).

Squamanita orientalis is similar to S. schreieri. However, the latter species has no cystidia. Furthermore, the former is a parasite on A. sepiacea, while S. schreieri is possibly associated with A. strobiliformis or A. echinocephala (Bas 1965).

Squamanita orientalis is also similar to $S$. sororcula and S. umbonata. However, S. orientalis differs from $S$. sororcula by its irregular fibrillose annular zone on the upper part of the stipe and ciliate squamules on the pileal margin, and larger cystidia (90-105 $\times 17$ $27 \mu \mathrm{m})$. In addition, there are ca. 50 and ca. 40 base differences in ITS and nrLSU regions between the two species respectively, and even though their hosts are identified as $A$. sepiacea for both species, there are ca. 25 different bases in the ITS region from host material. Squamanita umbonata differs from S. orientalis by its umbonate pileus, and narrower cystidia $(60-95 \times 9-20 \mu \mathrm{m})$, cylindrical to clavate fusiform mycocecidia.

Squamanita sororcula J. W. Liu \& Zhu L. Yang, sp. nov. - Fungal Names FN570782;

MycoBank 836586. (Figs. 11 and 12).
Etymology: -sororcula (Lat.): little sister, indicating a close relation with $S$. orientalis.

Diagnosis: S. sororcula differs from other species by without irregular fibrillose annular zone on the upper part of the stipe, with subglobose mycocecidia.

Type: China: Yunnan Province: Laojun Mountain, Jianchuan City, Dali, 26 38'51.792"N, 9949'10.43E, $2756 \mathrm{~m}$ elev., in a forest dominated by plants of Pinus yunnanensis, 10 Aug. 2019, Fa Li 237 (HKAS107306A holotype; GenBank Acc. nos.: 18S = MW258929, ITS = MW258850, $\quad \operatorname{nrLSU}=$ MW258902, $\quad$ TEF1- $\alpha=$ MW324507).

Description: Pileus medium-sized, ca. $45 \mathrm{~mm}$ diam, at first globose, then hemispheric, plano-convex with slightly incurved margin, thick-fleshed; surface buff $(6 \mathrm{~B} 7-8)$, viscid when wet, covered with buff $(6 \mathrm{~B} 7-8)$ floccose-fibrillose or slightly fibrillose squamules; pileal margin strongly appendiculate, with irregularly and densely corniform and fibrillose squamules derived from breaking up of the veil. Lamellae white (1A1), adnexed to adnate, moderately crowded, denticulate, rather thin, 6-7 mm wide. Stipe $50 \times 10-19 \mathrm{~mm}$, nearly cylindric, usually tapering upward; surface covered with buff (6B7-8) floccose-fibrillose or slightly fibrillose scaly zones, but not forming an irregular fibrillose annular zone at the upper part of the stipe, extreme apex white

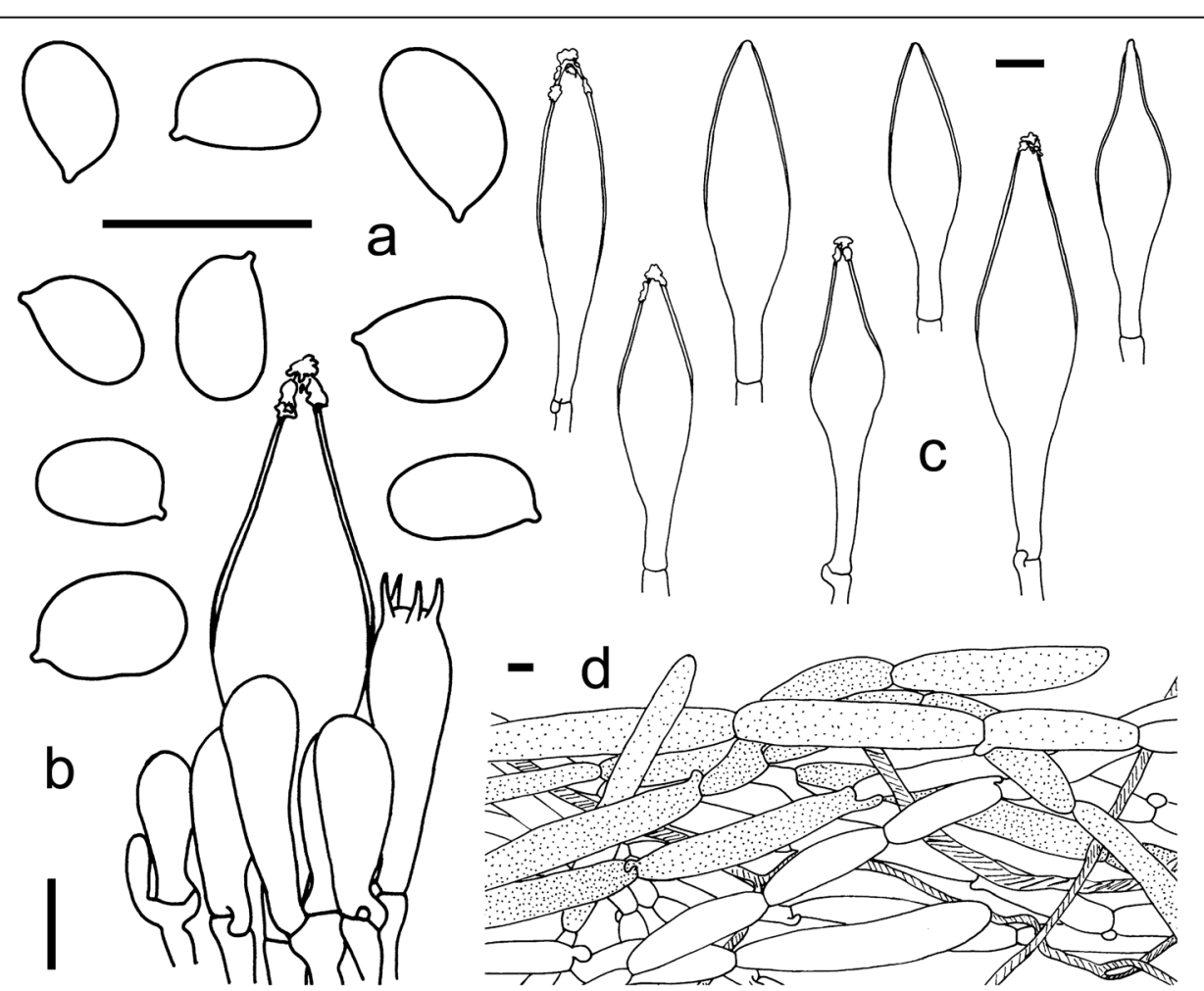

Fig. 12 Microscopic features of Squamanita sororcula (HKAS107306A, holotype). a Basidiospores. b Hymenium and subhymenium with one pleurocystidia covered with refractive incrustations. c Pleurocystidia, four of them covered with refractive incrustations. $\mathbf{d}$ Pileipellis section. Drawings by Jianwei Liu. Bars $=10 \mu \mathrm{m}$ 
and nearly smooth. Mycocecidia subglobose $35 \times 25 \mathrm{~mm}$, white (1A1) with brownish (6A4-5) to rusty (6B7-8) spots. The transitional zone between stem and mycocecidia with some irregular rings of tawny-ochraceous (6B7-8) or dingy brown (6E5), fibrillose, appressed, or erect, obliquely upward-pointing or lacerate scales. Context white (1A1), rather firm. Smell rather strongly musty when crushed.

Basidiospores [40/1/1] 5.5-7.5 (-9) $\times(3.5-)$ 4-5 (5.5) $\mu \mathrm{m}[\mathrm{Q}=(1.2-) 1.3-1.8(-2), \mathrm{Q}=1.6 \pm 0.8]$, broadly ellipsoid, ellipsoid to elongate, sometimes subreniform in side view. Basidia $20-35 \times 8-10 \mu \mathrm{m}$, subclavate, 4spored, fusiform to ventricose-fusiform, hyaline; sterigmata 4-5 $\mu \mathrm{m}$ long; basal septa often with clamps. Pleurocystidia and cheilocystidia numerous, 60-90 × 13$17 \mu \mathrm{m}$, fusiform to ventricose-fusiform, with obtuse to acute apex, nearly all upper part of cystidia are slightly thick-walled (up to $1.5 \mu \mathrm{m}$ ), sometimes with refractive incrustations, hyaline. Lamellar trama regular, composed of colorless, thin-walled hyphae 5-10 $\mu \mathrm{m}$ diam, branching, sometimes anastomosing; clamps present and common. Subhymenium consisting of 4-6 $\mu \mathrm{m}$ wide filamentous hyphal segments, narrow. Pileipellis a cutis with transition to a trichoderm at regular intervals, composed of loosely and more or less radially arranged, thinwalled hyphae $60-120 \times 5-20 \mu \mathrm{m}$, and at the upper of the pileipellis often with fine brownish granular incrustations on the yellowish to brownish filamentous hyphae, clamps present and common, occasionally with brown vacuolar pigments, $2-5 \mu \mathrm{m}$ wide; Mycocecidia composed of abundant subglobose to broadly clavate inflated cells $(20-55 \times 20-40 \mu \mathrm{m})$, and colorless and hyaline clampless filamentous hyphae, $2-6 \mu \mathrm{m}$ wide, and clamped filamentous hyphae nearly $5-15 \mu \mathrm{m}$ wide similar to those on the pileus; chlamydospores not observed.

Ecology: Parastic on Amanita sepiacea (HKAS107306B, ITS $=$ MW258871, TEF1- $\alpha=$ MW324505) growing on soil in forest dominated by Pinus yunnanensis.

Distribution: Currently known from Hunan and Yunnan Provinces, central and Southwest China.

Notes: Squamanita sororcula is similar to S. mira, S. orientalis, S. schreieri, S. umbonata, and other collections assigned to the "S. umbonata" complex. The differences between the first two and $S$. sororcula have been discussed above. Besides, $S$. sororcula differs from $S$. schreieri by the presence of cystidia and differs from $S$. umbonata by its subglobose mycocecidia.

Wang and Yang (2004) treated two collections (HKAS38127 and 38149) as "S. umbonata" collected from Hunan province, central China. Unfortunately, the collections have not been traced by us. However, the two collections are without an annular zone, and should be close to $S$. sororcula rather than $S$. orientalis.

\section{Key to Squamanita worldwide}

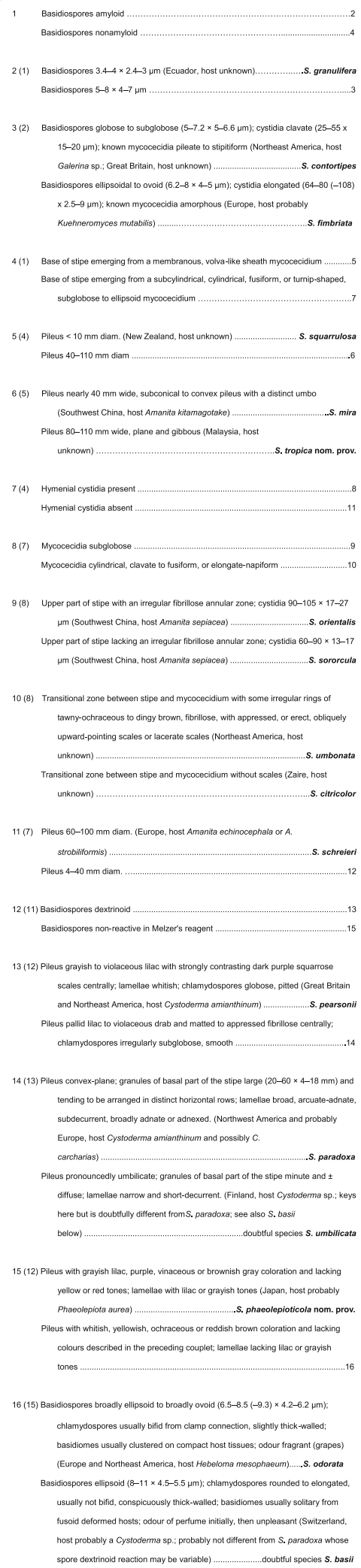




\section{DISCUSSION}

\section{Systematic position of Cystodermateae}

Singer (1986) included in Cystodermateae the following seven genera, viz. Cystoderma, Dissoderma (current name Squamanita), Horakia (current name Verrucospora), Phaeolepiota, Pseudobaeospora, Ripartitella, and Squamanita. Based on the phylogenetic analyses of Matheny and Griffith (2010), Matheny et al. (2015), Vizzini et al. (2019), Kalichman et al. (2020) and our present studies, three genera among Cystodermateae, viz. Cystoderma, Phaeolepiota, and Squamanita together with Leucopholiota and Floccularia can be assigned to the Squamanitaceae within Agaricineae (agaricoid clade). Pseudobaeospora was recognized as a member of the Tricholomataceae s. str. within Tricholomatineae (tricholomatoid clade) in the multigene phylogenetic analyses of Sánchez-García and Matheny (2017) and He et al. (2019). Molecular data from a species of Verrucospora, $V$. flavofusca, confirm placement in Agaricaceae s.lat. with strong statistic support (SH-aLRT/UFB/PP = 95.4/98/0.99) in our study (Fig. 2). Oberwinkler (1976) and Singer (1986) supposed that Horakia (now included in Verrucospora) belonged to Thelephorales or Cystodermateae of Agaricales, respectively, which are incorrect placements based on our molecular phylogenetic data. Phylogenetic placements of Ripartitella, and Cystodermella, which was separated from Cystoderma by Harmaja (2002), are unclear at present, although previous research based on nLSU, RPB1 and ITS molecular sequences indicated that Ripartitella and Cystodermella are near Cercopemyces (Baroni et al. 2014). Our study (Fig. 2) is consistent with Baroni et al. (2014), and these three genera are close to Hydnangiaceae in our phylogenetic tree (Fig. 2).

Saar et al. (2016) treated Phaeolepiota aurea as Cystoderma aureum because it was nested within Cystoderma. However, P. aurea, with large inamyloid fusoid and asperulate spores, differs from Cystoderma, species of which have amyloid, ellipsoid, oblong or fusiform and smooth spores. In our multigene phylogenetic tree (Fig. 2 ), and the supplementary trees of Varga et al. (2019), P. aurea nested within Cystoderma, but clustered with Cystoderma superbum (Fig. 2), a unique species commonly reported to be amyloid but in only a small area of the basidiospore surface, which is a morphotaxonomic character that differs from other species of Cystoderma. In the study of Matheny and Griffith (2010), and supplementary trees of that study (Additional files 1 and 2), a close relationship among $P$. aurea, Cystoderma and $C$. superbum was not well supported. Therefore, for the moment, we continue to recognize Phaeolepiota for $P$. aurea. Further studies with more samples and using more DNA makers are necessary to clarify the position of $P$. aurea and $C$. superbum in relation to other species of Cystoderma.
Up to now, 12 described species of Squamanita have been accepted, although Matheny and Griffith (2010: Table 1) listed 15, including three not validly published designations: S. cettoiana (nom. inval.), S. phaelepioticola (nom. prov.), and S. tropica (nom. prov.).

\section{Diversity of the "S. umbonata" species complex}

Our study indicated that material of "Squamanita umbonata" from the Northern Hemisphere clustered into two species complexes each consisting of several different species (Figs. 2 and 3), including S. orientalis, S. sororcula, and several undefined specimens. Morphological characteristics of collection R. E. Halling 7691 (NY79971) (Fig. 13) from Costa Rica are mostly consistent with the descriptions of the type (NY27684) by Sumstine (1914) and Bas (1965), with an umbonate pileus, cylindrical to clavate fusiform mycocecidia, and thin-walled cystidia. However, considering that the type of $S$. umbonata was from Pennsylvania, USA, we are reluctant to identify $R$. E. Halling 7691 as S. umbonata until molecular data from the type are available.

The collection H. E. Bigelow 17431 (NY2776224) (Fig. 13) has a subglobose mycocecidium, slightly smaller basidiospores $(5-7 \times 3.5-5 \mu \mathrm{m})$ and cystidia $(45-65 \times 12-18 \mu \mathrm{m})$ in comparison with those of $S$. umbonata, and the mycocecidium is composed of abundant inflated cells, indicating the possibility of Amanita as host. C. Bas 3808 (NY1840398) (Fig. 13) was published as S. umbonata by Bas (1965). However, Cortés-Pérez et al. (2014) showed that the upper parts of the cystidia in this collection were slightly to moderately thick-walled, which is consistent with our observations of the collection. Phylogenetically C. Bas 3808 forms a monophyletic branch with DAOM 199323 [GenBank accession no.: AF261508], submitted by Moncalvo et al. (2002), and may well be conspecific with that (Fig. 3). A collection from Italy ((HKAS107306A; Fig. 13) is sister to H. E. Bigelow 17, 431, C. Bas 3808, and DAOM 199323 (Fig. 3), and its hosts belong to the species complex of $A$. excelsa (GenBank accession no.: MW258872 and MW258873). Squamanita umbonata is also reported from Japan (Ikeda 1996), Italy (Vizzini and Girlanda 1997), and Mexico (Cortés-Pérez et al. 2014). Further efforts are necessary to reveal the species diversity of "S. umbonata" globally and delimit the constituent species, including a clear application of the name $S$. umbonata.

\section{Host preference or specificity of Squamanita species}

Our study reveals that the basidiomes of $S$. mira are composed of its own hyphae, while the mycocecidia also include hyphae of the host, which is consistent with the observations on S. paradoxa by Mondiet et al. (2007) 

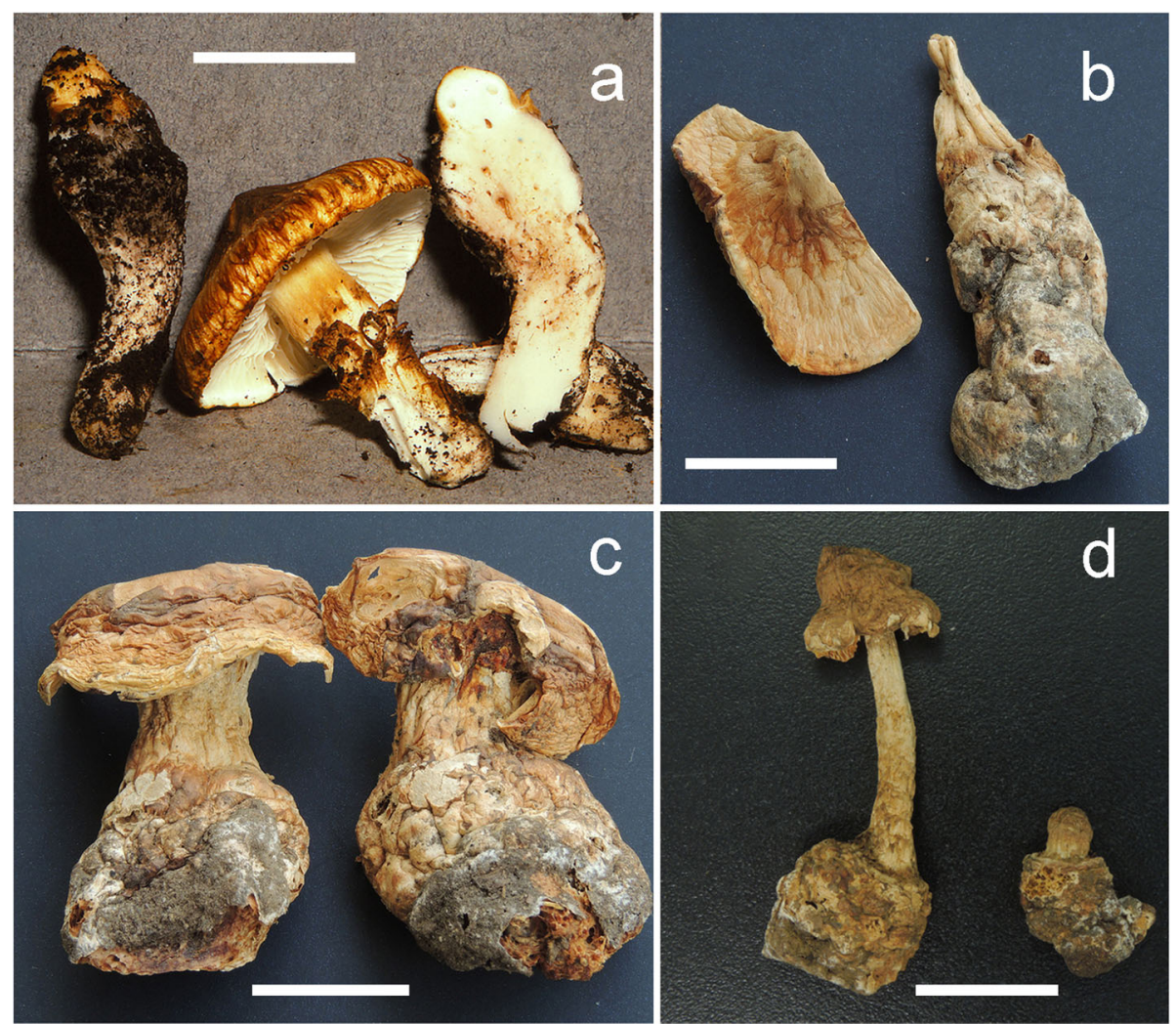

Fig. 13 Specimens of "Squamanita umbonata" included in this study. a Fresh basidiomes of R. E. Halling 7691 with cylindrical to clavate fusiform mycocecidium from Costa Rica. b C. Bas 3808 from USA with cylindrical mycocecidium. c H. E. Bigelow 17431 from USA with subglobose mycocecidium, a lump of clay is attached on the center of pileus of the specimen on the right, and the apical part of volval remnants on mycocecidium can be observed between clay and pileus under anatomical lens. d HKAS107325A from Italy with subglobose mycocecidium. Bars $\mathbf{a}=25 \mathrm{~mm}, \mathbf{b}-\mathbf{d}=20 \mathrm{~mm}$

and Griffith et al. (2019). Interestingly, host hyphae are found in the volval remnants that are attached to the pileal surface of S. orientalis (Figs. 5, 8, 10). This character may provide additional help for the host identification of Squamanita. Although sometimes the basidiomes of Squamanita may macromorphologically deform the hosts, most of the time the shapes of infected hosts (mycocecidia) still largely maintain consistent morphological characteristics with nearby uninfected basdiomes of the same species. Our study showed that S. orientalis, S. sororcula and "S. umbonata" (HKAS107325A) from Italy, with subglobose mycocecidia, are parasitic on $A$. sect. Validae, while $S$. mira, with the sheathing volva arising from the margin of a bulb, is parasitic on A. kitamagotake. Therefore, the shape and the size of the mycocecidia could be a reliable morphological character at species level.

\section{CONCLUSION}

The monophyly of the family Squamanitaceae was confirmed by multi-gene Bayesian phylogenetic analysis, with five genera, namely Cystoderma, Phaeolepiota, Squamanita, Floccularia and Leucopholiota falling in the family. Three new species from China, parasitizing two different species from two sections of Amanita, were uncovered and described based on morphological and molecular evidence. Furthermore, a multi-gene phylogenetic analysis on "Squamanita umbonata" from North America, Central America, Europe, and East Asia showed that it represents two species complexes harboring eight subclades. Further morphological studies are needed to reveal the species diversity and distribution patterns of "Squamanita umbonata".

\section{Abbreviations}

nrLSU: The large nuclear ribosomal RNA subunit; ITS: The internal transcribed spacers 1 and 2 with the 5.8S rDNA; 5.8S: $5.8 \mathrm{~S}$ gene; 18S: The small subunit region; TEF1-a: Translation elongation factor 1-a; RPB1: RNA polymerase II largest subunit; RPB2: RNA polymerase II second largest subunit;

CTAB: Cetyltrimethyl ammonium bromide; HKAS: Herbarium of Cryptogams, Kunming Institute of Botany of the Chinese Academy of Sciences;

ML: Maximum likelihood; UFB: Ultrafast bootstrap support values of IQTREE; SH-aLRT: The Shimodaira-Hasegawa-like aLRT test support values;

PP: Bayesian posterior probability; NY: The New York Botanical Garden

\section{Supplementary Information}

The online version contains supplementary material available at https://doi. org/10.1186/s43008-021-00057-z. 
Additional file 1. Maximum-Likelihood (ML) phylogenetic tree of Squamanitaceae inferred from ITS sequences, with SH-aLRT (left), ultrafast bootstrap (UFB) (right), only one of SH-aLRT > 80 or UFB > 95 for ML are indicated along branches (SH-aLRT/UFB). New species Squamanita mira, S. orientalis, S. sororcula are highlighted in boldface.

Additional file 2. Maximum-Likelihood (ML) phylogenetic tree of Squamanitaceae inferred from LSU sequences, with SH-aLRT (left), ultrafast bootstrap (UFB) (right), only one of SH-aLRT > 80 or UFB > 95 for ML are indicated along branches (SH-aLRT/UFB). New species Squamanita mira, S. orientalis, S. sororcula are highlighted in boldface.

\section{Acknowledgements}

We are very grateful to the fungaria of New York Botanical Garden, Eidgenössische Technische Hochschule Zürich, and also Reinhard Berndt, Fabrizio Boccardo, Li-Hong Han, Fa Li, and Gang Wu for providing specimens and images for this study; Shannon Asencio for providing helpful locality information on DAOM 199323 and DAOM 225481; and Bang Feng, Xiao-Bin Liu, Yan-Liang Wang, and Gang Wu for revising early manuscript.

\section{Adherence to national and international regulations} Not applicable.

\section{Authors' contributions}

Zhu L. Yang and Jian-Wei Liu designed the research. Jian-Wei Liu performed experiments, analyzed data and wrote the manuscript. Zhu L. Yang, Zai-Wei Ge, Egon Horak, Alfredo Vizzini, Roy. E. Halling revised the manuscript. Egon Horak, Alfredo Vizzini, Roy. E. Halling and Chun-Lei Pan also provided some specimens. The authors read and approved the final manuscript.

\section{Funding}

This work was supported by the Second Tibetan Plateau Scientific Expedition and Research Program (2019QZKK0503) and the Biodiversity Investigation, Observation and Assessment Program (2019-2023) of the Ministry of Ecology and Environment of China, and the International (Regional) Cooperation and Exchange Projects of the National Natural Science Foundation of China (No. 31961143010).

\section{Availability of data and materials}

The datasets generated for this study (Tables 1 and 2) can be accessed via GenBank: https://www.ncbi.nlm.nih.gov/genbank/. Alignments analysed during the current study are available at TreeBase: https://www.treebase.org/.

\section{Ethics approval and consent to participate}

Not applicable.

\section{Consent for publication}

Not applicable.

\section{Competing interests}

The authors declare that they have no competing interests.

\section{Author details}

${ }^{1}$ Yunnan Key Laboratory for Fungal Diversity and Green Development, Kunming Institute of Botany, Chinese Academy of Sciences, Kunming 650201, Yunnan, China. ${ }^{2}$ The Germplasm Bank of Wild Species, Kunming Institute of Botany, Chinese Academy of Sciences, 132 Lanhei Road, Kunming, 650201 Yunnan, People's Republic of China. ${ }^{3}$ CAS Key Laboratory for Plant Diversity and Biogeography of East Asia, Kunming Institute of Botany, Chinese Academy of Sciences, Kunming 650201, Yunnan, China. ${ }^{4}$ Schlossfeld 17, A-6020 Innsbruck, Austria. ${ }^{5}$ Department of Life Sciences and Systems Biology, University of Torino and Institute for Sustainable Plant Protection (IPSP-SS Turin), C.N.R, Viale P.A. Mattioli, 25, I-10125 Torino, Italy. ${ }^{6}$ Institute of Systematic Botany, New York Botanical Garden, 2900 Southern Blvd., Bronx, NY 10458-5126, USA. ${ }^{7}$ Mudanjiang Branch of Heilongjiang Academy of Agricultural Sciences, Mudanjiang 157041, Heilongjiang, China.
Received: 18 August 2020 Accepted: 16 February 2021

Published online: 03 March 2021

\section{References}

Baroni TJ, Kropp BR, Evenson VS, Wilhelm M (2014) Cercopemyces crocodilinus, a new genus and species related to Ripartitella, is described from North America. Mycologia 106(4):785-796. https://doi.org/10.3852/13-312

Bas C (1965) The genus Squamanita. Persoonia 3(3):331-359

Bas C, Læssøe T (1999) Squamanita granulifera sp. nov. A first record of Squamanita (Agaricales) from South America. Kew Bulletin 54:811-815. https://doi.org/10.2307/4110881

Bas C, Thoen D (1998) Squamanita citricolor, a new species from Central Africa. Persoonia 17:135-139

Cai Q, Cui YY, Yang ZL (2016) Lethal Amanita species in China. Mycologia 108: 993-1009. https://doi.org/10.3852/16-008

Cervini M (2008) Squamanita fimbriata, una spettacolare specie micoparassita. Rivista Di Micologia 51:213-220

Cortés-Pérez A, Guzmán G, Ramírez-Guillén F (2014) Squamanita umbonata (fungi, Agaricales, Tricholomataceae), primer registro en México. Actabotánica Mexicana 108:105-111. https://doi.org/10.21829/abm108.2014.202

Cui YY, Cai Q, Tang LP, Liu JW, Yang ZL (2018) The family Amanitaceae: molecular phylogeny, higher-rank taxonomy and the species in China. Fungal Diversity 91:5-230. https://doi.org/10.1007/s13225-018-0405-9

Endo N, Fangfuk W, Kodaira M, Sakuma D, Hadano E, Hadano A, Murakami Y, Phosri C, Matsushita N, Fukuda M (2017) Reevaluation of Japanese Amanita section Caesareae species with yellow and brown pileus with descriptions of Amanita kitamagotake and A. chatamagotake spp. nov. Mycoscience 58:457471. https://doi.org/10.1016/j.myc.2017.06.009

Fraiture A, Decock C, Leclerque A (2019) Squamanita paradoxa, a nice addition to the Belgian mycoflora. Sterbeeckia 35:84-89

Gardes M, Bruns TD (1993) ITS primers with enhanced specificity for Basidiomycetes-applications to the identification of mycorrhizae and rusts. Molecular Ecology 2:113-118. https://doi.org/10.1111/j.1365-294X.1993. tb00005.x

Griffith GW, Gajda KP, Detheridge AP, Douglas B, Bingham J, Turner A, Bowmaker V, Evans DA, McAdoo WG, Dentinger BTM (2019) Strangler unmasked: parasitism of Cystoderma amianthinum by Squamanita paradoxa and $S$. pearsonii. Fungal Ecology 39:131-141. https://doi.org/10.1016/j.funeco.201 8.11 .012

Guindon S, Dufayard JF, Lefort V, Anisimova M, Hordijk W, Gascuel O (2010) New algorithms and methods to estimate maximum-likelihood phylogenies: assessing the performance of PhyML3.0. Systematic Biology 59:307-321. https://doi.org/10.1093/sysbio/syq010

Gulden G, Bendiksen E, Brandrud TE (1977) New agaric, Squamanita fimbriata sp. nov., and a first find of Squamanita odorata in Norway. Norwegian Journal of Botany 24:155-158

Halama M (2016) Squamanita odorata (Agaricales, Basidiomycota), new mycoparasitic fungus for Poland. Polish Botanical Journal 61(1):181-186. https://doi.org/10.1515/pbj-2016-0008

Hall TA (1999) Bioedit: a user-friendly biological sequence alignment editor and analysis program for windows 95/98/NT. Nucleic Acids Symposium Series 41: 95-98

Harmaja H (1987) Studies on the agaric genera Singerocybe n. gen. and Squamanita. Karstenia 27:71-75. https://doi.org/10.29203/ka.1987.254

Harmaja H (2002) Amylolepiota, Clavicybe and Cystodermella, new genera of the Agaricales. Karstenia 42:39-48. https://doi.org/10.29203/ka.2002.386

He MQ, Zhao RL, Hyde KD, Begerow D, Kemler M, Yurkov A, McKenzie EHC, Raspé O, Kakishima M, Sánchez-Ramírez S, Vellinga EC, Halling R, Papp V, Zmitrovich IV, Buyck BED, Wijayawardene NN, Cui BK, Schoutteten N, Liu XZ, Li TH, Yao YJ, Zhu XY, Liu AQ, Li GJ, Zhang MZ, Ling ZL, Cao B, Antonín V, Boekhout T, Da Silva BDB, De Crop E, Decock C, Dima B, Dutta AK, Fell JW, Geml J, Ghobad-Nejhad M, Giachini AJ, Gibertoni TB, Gorjón SP, Haelewaters D, He SH, Hodkinson BP, Horak E, Hoshino T, Justo A, Lim YW, Menolli JN, Mešić A, Moncalvo JM, Mueller GM, Nagy LG, Nilsson RH, Noordeloos M, Nuytinck J, Orihara T, Ratchadawan C, Rajchenberg M, Silva-Filho AGS, Sulzbacher MA, Tkalčec Z, Valenzuela R, Verbeken A, Vizzini A, Wartchow F, Wei TZ, Weiß M, Zhao CL, Kirk PM (2019) Notes, outline and divergence times of Basidiomycota. Fungal Diversity 99:105-367. https://doi.org/10.1007/ s13225-019-00435-4

Henrici A (2013) Squamanita in Britain and Europe. Field Mycology 14(2):56-63. https://doi.org/10.1016/j.fldmyc.2013.03.008 
Hibbett DS (1996) Phylogenetic evidence for horizontal transmission of group I introns in the nuclear ribosomal DNA of mushroom-forming fungi. Molecula Biology and Evolution 13:903-917. https://doi.org/10.1093/oxfordjournals. molbev.a025658

Hoang DT, Chernomor O, Haeseler AV, Minh BQ, Vinh LS (2018) UFBoot2: improving the ultrafast bootstrap approximation. Molecular Biology and Evolution 35:518-522. https://doi.org/10.1093/molbev/msx281

Holden L (2005) Squamanita pearsonii collected in Aberdeenshire. Field Mycology 6:10-11

Horak E (1968) Synopsis generum Agaricalium. Beitr. Krypt. Flora Schweiz 13:1-741

Ikeda Y (1996) Colored Illustrations of Fungi of Ishikawa. The Hokkoku Shimbun, Japan

Imbach EJ (1946) Pilzflora des Kantons Luzern und der angrenzen Innerschweiz. Mitteilungen der Naturforschenden Gesellschaft Luzern 15:5-85

Jülich W (1981) Higher taxa of Basidiomycetes. Bibliotheca Mycologica 85:1-485

Kalichman J, Kirk PM, Matheny PB (2020) A compendium of generic names of agarics and Agaricales. Taxon 69(3):425-447. https://doi.org/10.1002/tax.12240

Katoh K, Kuma K, Toh H, Miyata T (2005) MAFFT version 5: improvement in accuracy of multiple sequence alignment. Nucleic Acids Research 33(2):511518. https://doi.org/10.1093/nar/gki198

Locquin M (1984) Mycologie générale et structurale. Masson, Paris

Matheny PB, Griffith GW (2010) Mycoparasitism between Squamanita paradoxa and Cystoderma amianthinum (Cystodermateae, Agaricales). Mycoscience 51: 456-461. https://doi.org/10.1007/S10267-010-0052-9

Matheny PB, Moreau PA, Vizzini A, Harrower E, Haan AD, Contu M, Curti M (2015) Crassisporium and Romagnesiella: two new genera of dark-spored Agaricales. Systematics and Biodiversity 13:28-41. https://doi.org/10.1080/14772000.2014 967823

Moncalvo JM, Vilgalys R, Redhead SA, Johnson JE, James TY, Aime MC, Hofstetter V, Verduin S, Larsson E, Baroni TJ, Thorn RG, Jacobsson S, Clémencon H, Miller OK (2002) One hundred and seventeen clades of euagarics. Molecular Phylogenetics and Evolution 23:357-400. https://doi.org/10.1016/S1055-7903 (02)00027-1

Mondiet N, Dubois MP, Selosse MA (2007) The enigmatic Squamanita odorata (Agaricales, Basidiomycota) is parasitic on Hebeloma mesophaeum. Mycological Research 111:599-602. https://doi.org/10.1016/j.mycres.2007.03. 009

Nagasawa E, Hongo T, Narita D (1990) Squamanita odorata (Agaricales) from Japan. Reports of the Tottori Mycological Institute 28:135-141

Nylander J (2004) MrModeltest 2.2. Computer software distributed by the University of Uppsala

Oberwinkler F (1976) Eineagaricoide Gattung der Thelephorales. Sydowia 28:359_ 361

Rambaut A, Drummond AJ (2009) Tracer. Version 1.5. Available at http://beast.bio. ed.ac.uk/Tracer

Redhead SA, Ammirati JF, Walker GR, Norvell LL, Puccio MB (1994) Squamanita contortipes, the rosetta stone of a mycoparasitic agaric genus. Revue Canadienne Botanique 72:1812-1824. https://doi.org/10.1139/b94-223

Rehner SA, Buckley E (2005) A Beauveria phylogeny inferred from nuclear ITS and EF1-alpha sequences: evidence for cryptic diversification and links to Cordyceps teleomorphs. Mycologia 97:84-98. https://doi.org/10.1080/1557253 6.2006 .11832842

Reid DA (1983) A second British collection of Squamanita paradoxa. Bulletin of the British Mycological Society 17:111-113. https://doi.org/10.1016/S0007-152 8(83)80038-8

Ronquist F, Teslenko M, Mark PVD, Ayres DL, Darling A, Höhna S, Larget B, Liu L, Suchard MA, Huelsenbeck JP (2012) MrBayes 3.2: efficient Bayesian phylogenetic inference and model choice across a large model space. Systematic Biology 61:539-542. https://doi.org/10.1093/sysbio/sys029

Saar I, Mešić A, Tkalčec Z, Peintner U, Kušan I (2016) Cystoderma carpaticum (Basidiomycota, Agaricales), a rare fungus newly recorded from Croatia. Phytotaxa 269(1):21-32. https://doi.org/10.11646/phytotaxa.269.1.3

Sánchez-García M, Matheny PB (2017) Is the switch to an ectomycorrhizal state an evolutionary key innovation in mushroom-forming fungi? A case study in the Tricholomatineae (Agaricales). Evolution 71:51-65. https://doi.org/1 0.1111/evo.13099

Singer R (1986) The Agaricales in modern taxonomy, 4th edn. Koelz Scientific Books, Koenigstein

Smith SA, Dunn CW (2008) Phyutility: a phyloinformatics tool for trees, alignments and molecular data. Bioinformatics 24:715-716. https://doi.org/1 0.1093/bioinformatics/btm619
Stridvall AS (1994) Släktet Squamanita Imbach i Sverige. Jordstjärnan 15:24-37 Sumstine DR (1914) New or interesting fungi. Mycologia 6:32-36

Trifinopoulos J, Nguyen LT, Haeseler AV, Minh BQ (2016) W-IQ-TREE: a fast online phylogenetic tool for maximum likelihood analysis. Nucleic Acids Research 44(W1):W232-W235. https://doi.org/10.1093/nar/gkw256

Varga T, Krizsán K, Földi C, Dima B, Sánchez-García M, Sánchez-Ramírez S, Szöllősi GJ, Szarkándi JG, Papp V, Albert L, Andreopoulos W, Angelini C, Antonín V, Barry KW, Bougher NL, Buchanan P, Buyck B, Bense V, Catcheside P, Chovatia M, Cooper J, Dämon W, Desjardin D, Finy P, Geml J, Haridas S, Hughes K, Justo A, Karasiński D, Kautmanova I, Kiss B, Kocsubé S, Kotiranta H, LaButti KM, Lechner BE, Liimatainen K, Lipzen A, Lukács Z, Mihaltcheva S, Morgado LN, Niskanen T, Noordeloos ME, Ohm RA, Ortiz-Santana B, Ovrebo C, Rácz N, Riley R, Savchenko A, Shiryaev A, Soop K, Spirin V, Szebenyi C, Tomšovský M, Tulloss RE, Uehling J, Grigoriev IV, Vágvölgyi C, Papp T, Martin FM, Miettinen O, Hibbett DS, Nagy LG (2019) Megaphylogeny resolves global patterns of mushroom evolution. Nature Ecology \& Evolution 3(4):668-678. https://doi. org/10.1038/s41559-019-0834-1

Vesterholt J (1991) Vellugtende Knoldfod-maske en parasit? Svampe 24:11

Vilgalys R, Hester M (1990) Rapid genetic identification and mapping of enzymatically amplified ribosomal DNA from several Cryptococcus species. Journal of Bacteriology 172:4238-4246. https://doi.org/10.1128/jb.172.8.423 8-4246.1990

Vizzini A, Consiglio G, Marchetti M (2019) Mythicomycetaceae fam. nov. (Agaricineae, Agaricales) for accommodating the genera Mythicomyces and Stagnicola, and Simocybe parvispora reconsidered. Fungal Systematics and Evolution 3:41-56. https://doi.org/10.3114/fuse.2019.03.05

Vizzini A, Girlanda M (1997) Squamanita umbonata (Sumst.) Bas, a mycoparasite of Inocybe oblectabilis (Britz.) Sacc. preliminary note. Allionia 35:171-175

Wang HC, Yang ZL (2004) Squamanita, a new record to China. Mycosystema 23: $146-148$

White TJ, Bruns T, Lee S, Taylor J (1990) Amplification and direct sequencing of fungal ribosomal RNA genes for phylogenetics. In: Innis MA, Gelfand DH, Sninsky JJ, White TJ (eds) PCR protocols: a guide to methods and applications. Academic Press California, San Diego, pp 315-322

Yang ZL (2005) Flora fungorum sinicorum. In: Amanitaceae, vol 27. Science Press, Beijing (in Chinese)

\section{Publisher's Note}

Springer Nature remains neutral with regard to jurisdictional claims in published maps and institutional affiliations.

\section{Ready to submit your research? Choose BMC and benefit from:}

- fast, convenient online submission

- thorough peer review by experienced researchers in your field

- rapid publication on acceptance

- support for research data, including large and complex data types

- gold Open Access which fosters wider collaboration and increased citations

- maximum visibility for your research: over $100 \mathrm{M}$ website views per year

At $\mathrm{BMC}$, research is always in progress.

Learn more biomedcentral.com/submission 